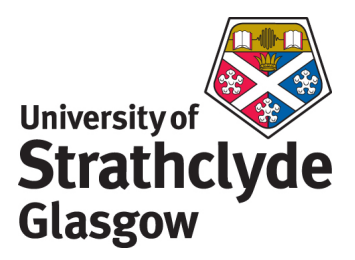

Quail, Francis J. and Hamilton, A. (2010) Detailed state of the art review for the different on-line/in-line oil analysis techniques in context of wind turbine gearboxes. ASME Journal of Tribology .

ISSN 0742-4787

http://strathprints.strath.ac.uk/28017/

This is an author produced version of a paper published in ASME Journal of Tribology . ISSN 0742-4787. This version has been peer-reviewed but does not include the final publisher proof corrections, published layout or pagination.

Strathprints is designed to allow users to access the research output of the University of Strathclyde. Copyright $(C$ and Moral Rights for the papers on this site are retained by the individual authors and/or other copyright owners. You may not engage in further distribution of the material for any profitmaking activities or any commercial gain. You may freely distribute both the url (http://strathprints.strath.ac.uk) and the content of this paper for research or study, educational, or not-for-profit purposes without prior permission or charge. You may freely distribute the url (http://strathprints.strath.ac.uk) of the Strathprints website.

Any correspondence concerning this service should be sent to The Strathprints Administrator: eprints@cis.strath.ac.uk 


\title{
Detailed State of the Art Review for the Different On-Line/In-Line Oil Analysis Techniques in Context of Wind Turbine Gearboxes Andrew Hamilton ${ }^{1}$, Dr Francis Quail ${ }^{1}$
}

\begin{abstract}
The main driver behind developing advanced condition monitoring (CM) systems for the wind energy industry is the delivery of improved asset management regarding the operation and maintenance of the gearbox and other wind turbine components and systems. Current gearbox CM systems mainly detect faults by identifying ferrous materials, water and air within oil by changes in certain properties such as electrical fields. In order to detect oil degradation and identify particles, more advanced devices are required so allow a better maintenance regime to be established. Current technologies available specifically for this purpose include Fourier Transform Infrared (FTIR) spectroscopy and ferrography. There are also several technologies that have not yet been or have been recently applied to CM problems. After reviewing the current state of the art, it is recommended that a combination of sensors would be used that analyse different characteristics of the oil. The information individually would not be highly accurate but combined, it is fully expected that greater accuracy can be obtained. The technologies that are suitable in terms of cost, size, accuracy and development are online ferrography, selective fluorescence spectroscopy, scattering measurements, FTIR, photoacoustic spectroscopy and solid state viscometers.
\end{abstract}

Keywords; condition monitoring, gearbox, wind turbine, in-line, on-line, oil analysis, particulate analysis, FITR spectroscopy, photoacoustic spectroscopy, sensors, fibre optics.

\footnotetext{
${ }^{1}$ Wind Energy Systems Doctoral Training Centre, Institute for Energy and the Environment, University of Strathclyde, 204 George Street, Glasgow, G1 1XW Email: francis.quail@eee.strath.ac.uk, andrew.hamilton@eee.strath.ac.uk Telephone: 0044 (0) 1415485769
}

\section{NOMENCLATURE}

$\begin{array}{ll}\mathrm{v} & \text { Kinematic Viscosity }\left(\mathrm{m}^{2} / \mathrm{s}\right) \\ \mu & \text { Absolute Viscosity }(\mathrm{kg} / \mathrm{m} \mathrm{s}) \\ \mathrm{AV} & \text { Acoustic Viscosity } \\ \rho & \text { Density }\left(\mathrm{kg} / \mathrm{m}^{3}\right) \\ \gamma & \text { Specific Gravity }\left(\mathrm{N} / \mathrm{m}^{3}\right) \\ \mathrm{P}_{\text {loss }} & \text { Power Loss } \\ \mathrm{f} & \text { frequency }(\mathrm{Hz}) \\ \lambda_{\text {exc }} & \text { Initial Emission Wavelength }(\mathrm{nm}) \\ \lambda_{\text {em }} & \text { Initial Excitation Wavelength }(\mathrm{nm}) \\ \Delta \lambda & \text { Wavelength Difference }(\mathrm{nm}) \\ \alpha & \text { Oil Parameter } 1 \\ \beta & \text { Oil Parameter } 2\end{array}$

\section{INTRODUCTION}

Ensuring reliability in the wind energy industry is often extremely difficult due to the stochastic nature of the resource, the isolated locations where the plants are built and the complex forces which interact in unexpected and damaging ways ${ }^{1}$. These conditions have led to high failure rates for various different components in the turbine with the gearbox being the most problematic for various reasons ${ }^{2,3}$. Figure 1 shows the failure frequency and downtime of different wind turbine components. Whilst the failure rate is lower than most components, the downtime is far greater.

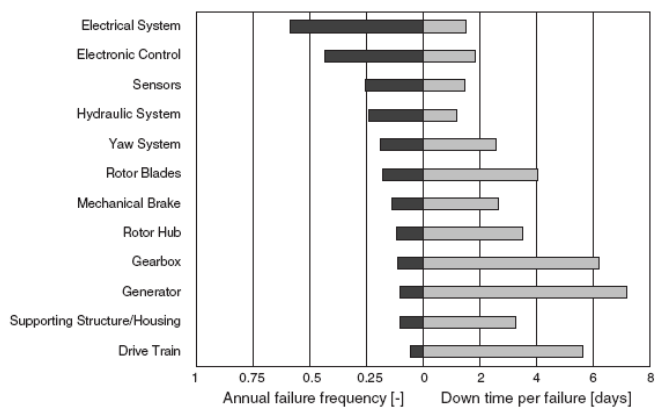

Figure 1: Failure frequency and downtime for wind turbine components ${ }^{4}$
The component itself is expensive so repairs or replacements within the operational lifetime will impact the operational economics of the wind turbine. An $£ 800$ bearing could fail, leading to the replacement of a $£ 300,000$ gearbox with a $£ 50,000$ per day hired crane, excluding the costs incurred from downed electricity production ${ }^{5,6}$. These problems will be exacerbated when more wind farms are located offshore ${ }^{7}$ due to greater forces, more isolated conditions and increased access costs. One method to improve reliability is to monitor the condition of components in the wind turbine using sensors which measure different variables. Using this data with statistical methods, the current and future condition of components may be accurately assessed ${ }^{8}$. This will allow decisions on when maintenance or replacements occur to be made with a higher degree of certainty. According to McMillan and Ault, it is envisioned that this will reduce failure rates, allow an efficient maintenance regime to be established and reduce overall costs that are incurred due to downed wind turbines ${ }^{9}$.

The gearbox is an ideal component to monitor for several reasons. The gearbox is responsible for many of the maintenance costs due to repairs, replacements and turbine downtime. There are many different indicators of its condition, such as abnormal vibrations and acoustic emissions $^{10,11}$. However in a wind turbine nacelle these indicators can be influenced by other components such as the generator and wind loads. It is believed that these factors will reduce the overall accuracy of vibration and acoustic emission analysis. Another major indicator of the gearbox condition is the state of the gearbox lubricant ${ }^{12}$. Lubrication and oil has to be applied in various different locations such as bearings to ensure optimal performance. In contact machinery, materials begin to wear and ultimately break depending on the types of loads that are applied. These wear particles are often liberated and become suspended in the oil which can then be analysed ${ }^{13}$. Since the majority of materials in a gearbox are metallic, most online systems of detection have relied on identifying changes in electromagnetic properties of the oil ${ }^{14}$. However the main problem is interpreting what these changes actually mean. A large number of iron particles which are liberated from the bearings will give the same change in electromagnetic properties as the same amount of iron from the gears. It is 
clear though these are two separate problems and one may be more significant than the other. In order to establish an effective maintenance regime, there must be a high degree of certainty which particular area is problematic ${ }^{15}$.

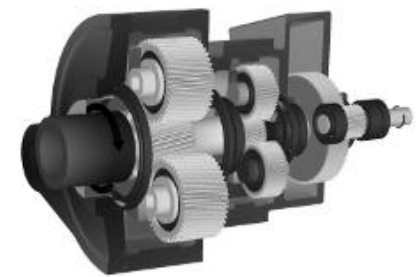

Figure 2: Computational model of a planetary gearbox ${ }^{16}$

As well as identifying particles suspended within the oil, the quality of the oil itself is crucial to the operation of the gearbox with the rate of degradation being affected by several different factors including temperature, oxidation, contaminants and time ${ }^{13}$. By assessing the state of the oil, a far more efficient and proactive approach to maintenance may be taken, rather than waiting for faults to occur and needlessly changing oil. Modern lubricants for gearboxes include many different additives to alter chemical properties which are vital to the operation of the gearbox ${ }^{17}$. Any small change to the chemical composition of these mainly synthetic oils may have disastrous results and so constant monitoring is required to give wind turbine operators advanced warning of any problems.

There is currently a large variety of technology already available for these purposes, however most are offline systems and the effectiveness of each varies as much as the technology ranges. There are many technologies that have not been considered in CM yet or have only just started to be considered. The purpose of this review is to establish the current technologies available, examine any technology that could be applied potentially and provide recommendations for a wind turbine gearbox online/inline $\mathrm{CM}$ solution based on the findings.

\section{OIL ANalysis}

\section{PHYSICS AND CHEMISTRY OF OIL ANALYSIS}

There are several factors that affect the properties of lubricating oil which can be monitored to give an indication of its condition and allow predictions to be made about its future performance. In industry typically the following parameters are used to characterise the oil quality ${ }^{18}$ :

- Acid Content

- Viscosity

- Water Content

- Oxidation Level

- Temperature

Several interdependencies exist between these parameters such as oxidation and acidity levels. Ideally, any new remote CM system would have to track all of these properties to effectively evaluate the current and potentially predict the future state of the lubricants in the gearbox. It could be argued that acidity and water are the most important as these will give provide data on the potential corrosion state of gearbox components $^{19}$. However, acidity is closely related to oxidation and so it may be argued that it is equally important. Also, the thermal breakdown of the oil into different components may reduce its lubricating capabilities.

\section{A. Acid Content}

The level of acid in lubricating oil can be affected by a number of factors but is generally related to the amount water, oxidation levels, types of additives and chemical breakdown products. The most common types of acid found in gearbox lubrication are oxoacids, which are composed of one oxygen atom, one hydrogen atom bonded to the oxygen atom and one other element, usually carbon. Within the broad area of oxoacids, the most common group of acids to be found are carboxylic acids, nitric acid and sulphuric $\operatorname{acid}^{20}$. The presence of the nitric and sulphuric is usually attributed to combustion products of an engine.

$$
\begin{array}{ccc} 
& \mathbf{O} & \mathrm{O} \\
-\mathrm{O}-\mathrm{H} & -\mathrm{C}- & \| \\
-\mathrm{C}-\mathrm{O}-\mathrm{H}
\end{array}
$$

Figure 3: Left - Hydroxyl, Middle - Carbonyl, Left - Carboxylic Acid

In Figure 3, the structure of carboxylic acid is shown. Its presence is usually detected by the carbonyl group that is attached, either by a chemical reaction that breaks the double bond or by spectroscopic methods ${ }^{21}$. Understanding the mechanisms which create these acids as well as their chemical properties and structures is vital in identifying them.

The standard method of quantifying the acid content of oil is to use the Total Acid Number (TAN). The TAN is the amount of a standard base, usually potassium hydroxide $(\mathrm{KOH})$, which is required to neutralise the acid present in the oil. However, the TAN only indicates the value of acid concentration and not its strength.

\section{B. Viscosity}

Viscosity is a measurement of the internal friction within a liquid at a given temperature. It is particularly important for oils as it will determine their ability to form a lubricating film on gearbox components. Viscosity is affected by a variety of factors including, lubricant degradation, TAN and water contamination, but it mainly affected by temperature ${ }^{22}$, as shown in Figure 4. This is reason why measurements must include the temperature of the fluid. There are three main ways in which viscosity can be defined: absolute, kinematic and acoustic viscosity.

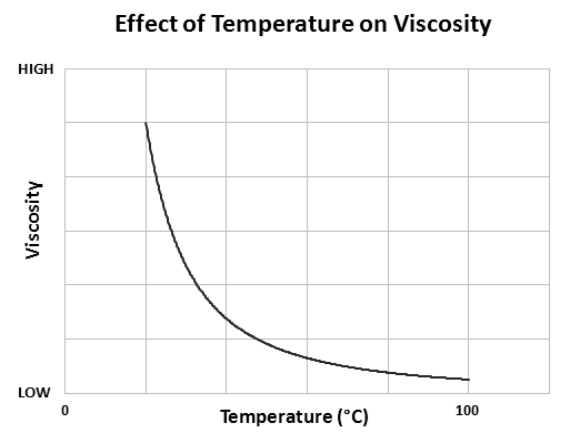

Figure 4: General effect of temperature in the viscosity of oils ${ }^{22}$ 


\section{1) Absolute (Dynamic) Viscosity}

Absolute viscosity is the value of a fluid resistance to flow for a given temperature. To measure it, an external force is required to move the fluid through a capillary. The effort required to achieve this in a given time is measured as a function of the input force with units of $\mathrm{Ns} / \mathrm{m}^{2}$. This type of viscosity measurement is the most common for onsite analysis $^{23}$.

\section{2) Kinematic Viscosity}

The kinematic viscosity is the ratio of the absolute viscosity to the internal inertia force of the liquid, which is characterised by the density.

$$
v=\mu / \rho
$$

Equ (1) shows the relationship between kinematic viscosity, absolute viscosity and density. It is usually determined by measuring the time for a sample to pass through a capillary due to gravity.

\section{3) Acoustic Viscosity (AV)}

$\mathrm{AV}$ is the least used method of measuring fluid viscosity. It is defined as the absolute viscosity multiplied by the specific gravity of the sample, as shown in Equ (2).

$$
A V=\alpha \mu^{\beta}
$$

Since AV is not as common in defining a fluids viscosity, a correlation must be established between either kinematic or absolute viscosity in order to comply with industrial standards ${ }^{24}$.

\section{Water Content}

Water can exist in oil in 3 different states: dissolved, free and emulsified, with each of these causing different problems for lubrication effectiveness. The presence of free water in lubricating oil will cause corrosion to any metallic components. Contact with iron and oxygen will result in various iron oxides (rust) forming. This will cause contamination of the lubricant due to rust particles, surface damage due to the formation of oxides, scoring and block cooling passages. The corrosion can lead to ionic compounds existing within the oil, further disrupting its chemical properties. Emulsified water can cause several changes to occur to additives, depending on their chemical composition. Since a large number of commercial synthetic lubricants rely on the properties of additives, changes are significant ${ }^{25}$. Hydrolysis is the process of water breaking down a compound by using its two ionic components, $\mathrm{H}^{+}$and $\mathrm{OH}^{-}$. These ions will try and bind with different parts of a polymer, resulting in its structural breakdown, causing reduced lubricant effectiveness, changes to viscosity and potentially greater corrosion due to the presence of free ionic molecules.

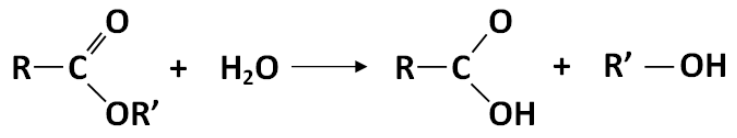

Figure 5: Hydrolysis reaction of an ester (N.B. R represents a general molecule $)^{20}$

In Figure 5, a simple hydrolysis reaction is shown of an ester, often found in a variety of lubricants and oils ${ }^{26}$. In addition to splitting the structure, 2 hydroxyl groups are creating which may react with other groups, further destabilising the lubricant. When water disassociates into oxygen and hydrogen, several problems can occur. Oxidation rates are accelerated due to the presence of oxygen and also metal particles which have formed oxides. Hydrogen will cause embrittlement of the iron, weakening steel components. As these cracks grow, failure probabilities increase.

\section{Oxidation}

Oxidation levels can be established by monitoring reaction by-products such as ketones, esters, aldehydes, carbonates and carboxylic acids ${ }^{27}$. Some of these molecules are dissolved in the oil or remain suspended due to the additives in the oil. The effect of prolonged oxidation is that the lubricant becomes more acidic which leads to corrosion and can also change the viscosity. The additional oxygen atoms can either change the structure or break it up entirely into new molecules, both have serious consequences for the operating condition of the lubricant.

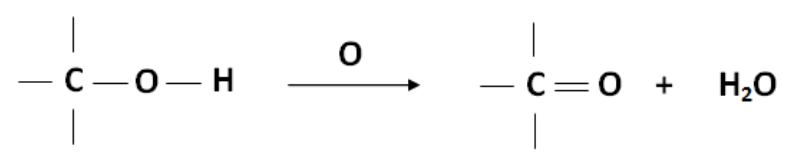

Figure 6: Oxidation of a hydroxyl group

In Figure 6, oxidation of a hydroxyl group is shown. Whilst being an extremely simplified representation, it demonstrates the associated problems. First, the creation of water is significant for the reasons mentioned in the previous section. The reaction also results in a carbonyl group $(\mathrm{C}=\mathrm{O})$, which can become carboxylic acid if there is another hydroxyl group attached. Other effects of oxidation include by products, such as hydroperoxides, and becoming large polymers which develop long enough to start sludging in the oil. This process increases the viscosity significantly, adversely affecting the lubricants performance.

\section{E. Temperature}

The temperature of the oil is important due to its effect on the parameters already mentioned. As the temperature increases, rates of oxidation increase, viscosity decreases, lubricant components begin to suffer from thermal degradation and additives can become unstable. Whilst simple to measure, temperature is still critical. Coking in gearboxes is related to temperature. This is extremely detrimental to bearings and cooling passages, resulting in reduced flow in certain areas.

\section{CURRENT TECHNOLOGIES}

\section{A. Karl Fischer Water Test}

The Karl Fisher water test analyses the volume of water in a sample by quantifying the oxidation of sulphur dioxide ( $\mathrm{SO} 2$ ) by iodine $\left(\mathrm{I}_{2}\right)$ in the presence of water. There are two methods of achieving this reaction: volumetric or coulometric titration. 


$$
\mathrm{I}_{2}+\mathrm{SO}_{2}+2 \mathrm{H}_{2} \mathrm{O} \rightarrow 2 \mathrm{HI}+\mathrm{H}_{2} \mathrm{SO}_{4}
$$

The coulometric titration cell consists of two parts, a main and an anode compartment as shown in Figure 7. The reason for the separation is to prevent the reaction from reversing and giving an inaccurate result ${ }^{28}$. In the main, the sample which is to be analysed is mixed with an alcohol, a base, SO2 and $\mathrm{I}_{2}$ which is known as the anode solution and also contains the electrical cathode. The alcohol used is generally methanol or diethylene glycol monoethyl ether while the base may be imidazole or primary amines ${ }^{29}$.

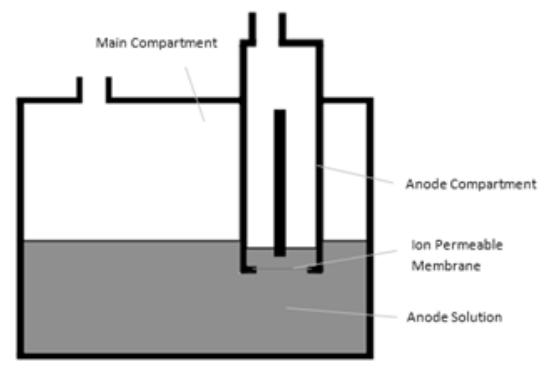

Figure 7: Coulometric titration diagram ${ }^{30}$

The anode compartment contains the electrical anode which is submersed in the solution but is separated from the main compartment by an ion-permeable membrane. In the reaction, water and iodine are consumed in a 1:1 ratio, which means when excess $\mathrm{I}_{2}$ starts to appear, all the water in the sample has reacted. The excess $I_{2}$ is detected using a second pair of indicator electrodes maintain a constant current. When the reaction has finished, the excess $\mathrm{I}_{2}$ causes a sharp decrease in voltage across the electrodes. The amount of water that is in the sample is determined by measuring the charge required in order to fully complete the reaction: $1 \mathrm{mg} \mathrm{H} 2 \mathrm{O}=10.72 \mathrm{C}^{31}$. This method of titration can detect water as low as $1 \mathrm{ppm}^{32}$ which is suitable for gearbox condition monitoring.

The method of volumetric titration operates in the same manner as coulometric but instead the iodine is added into the solution until no more reacts with water. This point is established using a double platinum pin indicator electrode. A microprocessor is used to determine the volume of water in the sample from the amount of iodine that consumed in the solution. This method of titration however is not suitable for $<100$ ppm, which would make it unsuitable for the low level water detection in gearboxes ${ }^{33}$.

There is low potential to develop a Karl Fischer coulometric titration module as an online or inline sensor system. Water detection is highly accurate, but other systems would be needed to identify other parameters. Also the system needs a supply of iodine, alcohol and reagent base which would have to be incorporated. When the supplies run out, the system would have to be replenished which would be undesirable in the context of offshore wind farms.

\section{B. Calcium Hydride Water Test}

Water reacts with calcium hydride $\left(\mathrm{CaH}_{2}\right)$ to produce hydrogen which relates to the water content of the sample. Equ. (4) shows the chemical reaction. By measuring the volume of liberated gas, the amount of water can be determined.

$$
\mathrm{CaH}_{2}+2 \mathrm{H}_{2} \mathrm{O} \rightarrow \mathrm{Ca}(\mathrm{OH})_{2}+2 \mathrm{H}_{2}
$$

There is low potential to develop the calcium hydride test into an online or inline system. Field portable test kits have been developed by oil contamination company, Dexsil ${ }^{\mathrm{TM}}$ which could be developed into online kits. However, the lowest level of water detection is limited to $50 \mathrm{ppm}$, unsuitable for gearbox detection ${ }^{34}$. The system would also need to be supplied with $\mathrm{CaH}_{2}$, adding a further complication to the system.

\section{Infra-Red Spectroscopy (IRS)}

IRS operates on the principle that chemical bonds will absorb a unique wavelength of infrared radiation corresponding to their resonant frequency ${ }^{35}$. This is the frequency at which a particular mode of the molecule will vibrate at, very similar to the frequencies associated with structural modes of buildings. Figure 8 shows the first 3 modes of a simple molecule.

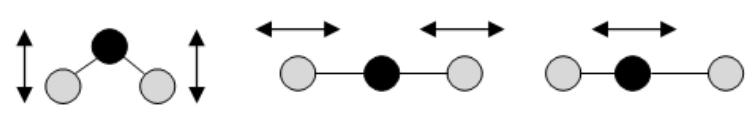

Figure 8: First 3 vibrational modes for a simple molecule ${ }^{36}$

Absorption IRS is the most common method used to identify molecules. In its simplest form, a beam of monochromatic IR radiation is directed at a reference sensor to detect the wavelength emitted ${ }^{37}$. The same beam is then directed at the sample with a sensor positioned underneath that will detect if the beam passes through or has been absorbed and the process is repeated for the desired range of IR wavelengths. The main problem with this method is the length of time it requires to analyse all the desired wavelengths. The process may take up to $10 \mathrm{~s}^{37}$ to analyse the sample fully. However, a process known as Fourier Transform Infrared Spectroscopy (FTIR) may be used instead. Instead of using a monochromatic source, a beam consisting of a range of wavelengths will be passed through the sample and the values of wavelength which are absorbed are recorded by the sensors ${ }^{37}$. This process is repeated several times but using different combinations of wavelength values in order to establish separate data points which can be interpreted using Fourier mathematics. Additional software is required to perform the transform but the time taken is reduced to between $0.25-1 \mathrm{~s}^{37}$, allowing many samples to be analysed rapidly. 


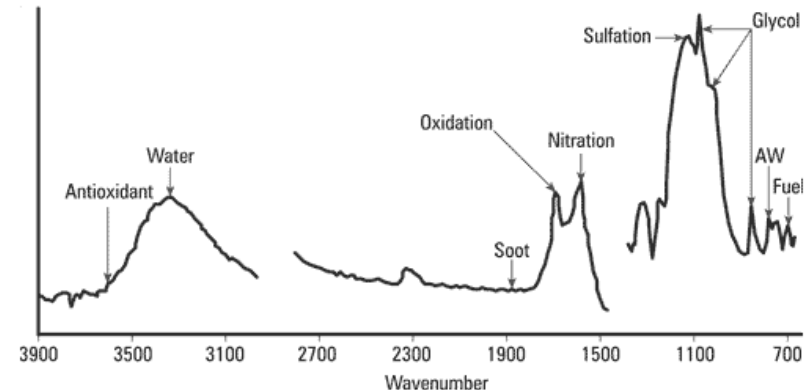

Figure 9: Amount of IR radiation absorbed for each particular component of a sample ${ }^{38}$

FTIR can determine the level of oxidation by identifying carbonyl $(\mathrm{C}=\mathrm{O})$ due to its unique bond absorption wavelength. The wavelength which will be absorbed by this bond is approximately 6300 nanometres $(\mathrm{nm})^{39}$. In this region, IR energy is absorbed by the carbon-oxygen bonds in the oxidized oil and very few compounds found in petroleum lubricants have significant absorbencies in this area. Monitoring this region is a direct measurement of the oxidation level. However FTIR does have problems. In complex liquids such as lubricating oils, there are a variety of polymers, bonds and vibrational modes which are affected by temperature and contaminants.

Another main benefit of using IRS is water can be identified simultaneously with other chemicals related with lubricants, rather than using a separate system such as the Karl Fischer test. However the ability of FTIR to detect water particles starts to diminish below a concentration of $500 \mathrm{ppm}$ in synthetic oils ${ }^{40}$. Accuracy can be achieved until $100 \mathrm{ppm}$, but there is a degree of uncertainty. Figure 9 shows the detection of various chemicals in an oil sample. Oxidation has a defined peak, indicating precise detection capabilities whilst water has a broad peak, indicating uncertainty, especially when smaller concentrations are analysed.

There is high potential in developing FTIR as an online/inline sensor system. There are currently commercially available hand held IRS devices such as the Spectro FluidScan $\mathrm{Q}^{1000 @}$ which has the ability to measure TAN, TBN, oxidation, nitration, sulfation, glycol, water and glycerine within 1 minute $^{41}$. Whilst the cost is high and no remote application has been tested, there is a possibility of creating a miniaturised IRS sensing system. The main problem is the ability to detect water since most portable commercial IRS operates with 100 ppm as the lowest detection level.

\section{Photoacoustic Spectroscopy (PAS)}

PAS is considered a photothermal technique as light is absorbed by a sample which causes a change in the thermal energy structure of molecules. The change can be observed by measuring temperature or density of the sample. Eventually the sample would return to its original energy state due to heat transfer with the surrounding environment. The process of hitting the sample with light can modulated, so that there is a cycle of energy absorption and emission. This cycle of modulated light can be increased so that the sample does not have time to expand and contract to the modulated light source, resulting in a change in pressure which causes an acoustic wave that can be detected with hyper sensitive microphones or piezoelectric devices ${ }^{42}$. Figure 10 shows the layout of a PAS sensor.

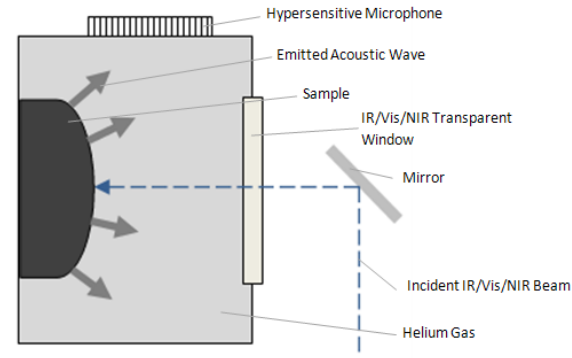

Figure 10: Diagram of classic PAS sensor equipment ${ }^{44}$

The method for detecting which chemicals are present is similar to IR spectroscopy. In standard PAS, the modulated light source is usually a high powered xenon or halogen lamp which is passed through a monochromator to allow selection of the desired wavelength of light ${ }^{43}$. If the sample absorbs a particular wavelength, the molecules will become excited and then relax, generating heat. This occurs for every cycle of modulated light that hits, resulting in a series of thermal waves that travel through the sample until reaching the surface. At this point the heat is transferred to the contacting gas (usually helium) as an acoustic wave which then travels to the microphone. Individual chemicals and elements are identified by the amplification of this sound. Compounds that have a higher absorption coefficient will generate a wave with greater amplification. To fully analyse a sample, a range of monochromatic wavelengths can be used. Since PAS analyses the thermal waves that generate acoustic waves, it is unaffected by surface scattering effects unlike other types spectroscopy. This allows the analysis of oils which have suspended solid particles.

PAS has the ability to detect trace levels of water within a sample $(\leq 50 \mathrm{ppm})$ in petroleum oils ${ }^{44}$ which is very desirable in the context of gearboxes. However these detection levels have so far been only achieved as an offline experimental system. The equipment used consisted of a high powered mirror, optical filters and an expensive Nd-YAG (Neodymium-doped Yttrium Aluminium Garnet) laser which are unsuitable for use in a remote sensory device ${ }^{44}$.

The potential to develop PAS as an online sensor is high. There is currently significant research into miniaturising the technology, with sensors cells ranging in size from $5 \mathrm{~mm}^{2}$ to $500 \mathrm{~mm}^{2}$ that can be integrated as part of a remote system ${ }^{45}$. Currently, the accuracy of miniaturised devices for detecting the desired oil parameters has not been established. However, the accuracy of miniaturised PAS sensors has been tested in other fields such as chemical reactors. Several PAS sensors measuring $14.4 \mathrm{~cm}^{2}$ have demonstrated considerable accuracy in detecting shifts between levels of gas such as $\mathrm{CO} 2$ and propane $^{46}$. As PAS analyses thermal waves that propagate through the sample and manifest themselves as acoustic waves, smaller samples actually increase the detection capabilities, meaning that it is very suitable for micro sensors.

\section{E. Capillary Tube Viscometer}

An oil sample is contained in a U-shaped capillary tube and is then moved by suction so that the volume on either side of 
the bend is uneven. Figure 11 shows the layout of a classic capillary tube viscometer. The suction is then released, allowing the oil to flow back to the equilibrium position and the time taken is measured. The flow rate is proportional to the kinematic viscosity of the oil sample, with less viscous oils flowing faster than more viscous. The temperature at which the oil sample is taken is usually $40^{\circ} \mathrm{C}$ for industrial oils or at $100^{\circ} \mathrm{C}$ for engine oils ${ }^{47}$.

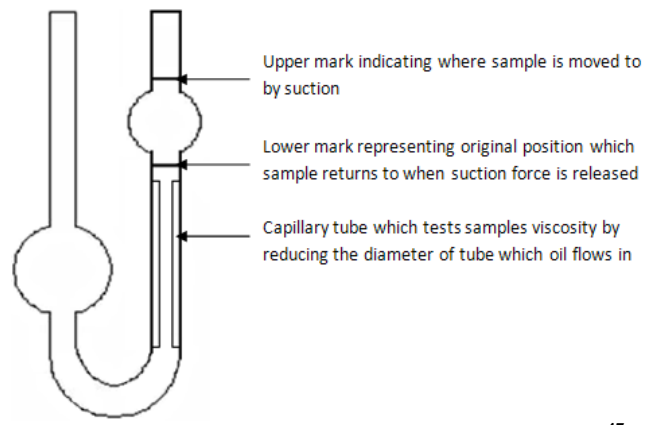

Figure 11: Diagram of capillary tube viscometer ${ }^{47}$

A capillary tube viscometer is highly effective at establishing viscosity. The equipment required is not costly, but relies on constant gravity to establish accurate viscosity measurements.

\section{F. Rotary Viscometer}

An oil sample is placed in a glass tube which is encased in a chamber with a constant temperature. A metal spindle runs through the oil and can only rotate at a constant rpm so in order to turn the spindle, sufficient torque must be applied. If an oil sample has high viscosity, it will require a larger amount of torque to turn the spindle $e^{48}$.

There is low potential to develop the rotary viscometer into a remote sensor. Despite simple technology, the additional costs to have a separate system that requires moving parts, a relatively large oil sample and accurate calibration that may be affected by vibration makes it unsuitable for deployment in a wind turbine.

\section{G. Solid State Viscometer}

Solid state viscometers measure the acoustic viscosity of a given sample using the properties of shear wave propagation. A shear wave is a type of energy transfer through a material, where the direction of wave propagation is perpendicular to the direction of motion. Figure 12 shows how a shear wave propagates through a material.

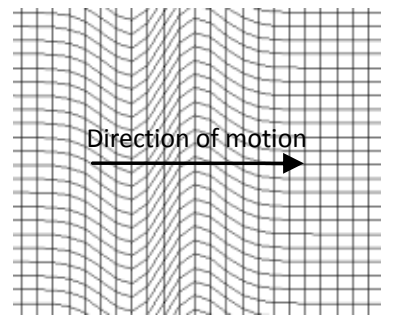

Figure 12: Distortion of material due to movement of shear wave

These waves can move through most materials but changes occur when the wave transfers between materials. At the transition point, the amount of energy that is lost from the wave is directly proportional to the frequency of the wave, the density of the new material and the absolute viscosity of the new material. Equ (5) shows the relationship between the different parameters.

$$
\mathrm{P}_{\text {loss }}^{2} \sim \mathrm{f} \times \rho \times \mu
$$

If an acoustic wave resonator is placed in contact with a lubricant and a low frequency shear wave is transmitted through it, a layer of the oil will hydrodynamically couple to the surface of the resonator. Since the frequency and amplitude of the wave is fixed (frequency is set by the design of the sensor and the amplitude is set by the power of the electrical signal sent), the layer thickness and energy dampening (power loss) will be determined by the viscosity and density. If the original power in the wave is known and the power that is left once the wave enters the oil, the difference can be found and subsequently, the viscosity. In order to make this comparison, the wave in the oil must be measured.

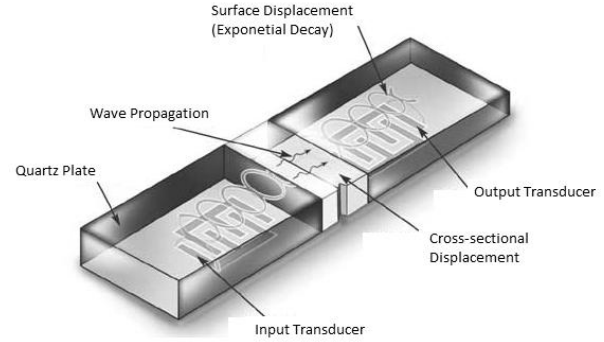

Figure 13: Layout of acoustic wave resonator sensor $^{49}$

To achieve this, a set of electrodes are sealed from the oil, but are situated below the oil sample. When the wave passes through, the power will be attenuated and the new wave value is measured by the electrodes. The value of acoustic viscosity can be determined from this and then converted to a more useful term such as absolute viscosity using a previously determined relationship for the particular lubricant. The oil is not adversely affected by the process as the area which forms the hydrodynamic coupling in the micron scale. As mentioned previously, it is essential to report the temperature of the oil sample before an assessment of the viscosity can be made.

There is high potential to develop a solid state viscometer as an online or inline system. There are currently several sensors designed for this purpose that have high correlations between data measured using AV and laboratory tested samples using conventional methods ${ }^{49}$. Since it is not standard practice to state the acoustic viscosity of a sample, a conversion must be made to either kinematic or absolute viscosity. A critical area of these sensors is establishing a relationship between these measurements as it will change depending on the type of oil that is being analysed ${ }^{49}$. In addition, the sizes of these sensors are small, measuring approximately 12 to $24 \mathrm{~cm}^{3}$ which would be ideal for integration into a wind turbine gearbox. The accuracy of solid state viscometers in analysing lubricants for gearboxes would have to be investigated further to ensure additives, vibrations in the nacelle and temperature variations do not have adverse effects on measurements. 


\section{H. Fluorescence Spectroscopy}

\section{1) Concept}

Fluorescence spectroscopy uses light to excite electrons that then emit electromagnetic radiation which is detected by a spectrometer. The wavelength emitted and its intensity is characteristic of the molecules present and their amount in the sample. A single wavelength of light is selected to excite the sample by using a source that emits only one wavelength such a laser or using a halogen lamp can be combined with a monochromator. The light hits the sample, causing an increase in the energy of the molecule which results in a vibrational mode $\mathrm{e}^{50}$. The molecule then drops back down to its ground state, releasing photons of a particular wavelength in the process. The wavelength emitted is dependent on several factors such as the molecule structure, its vibrational modes and the surrounding molecules.
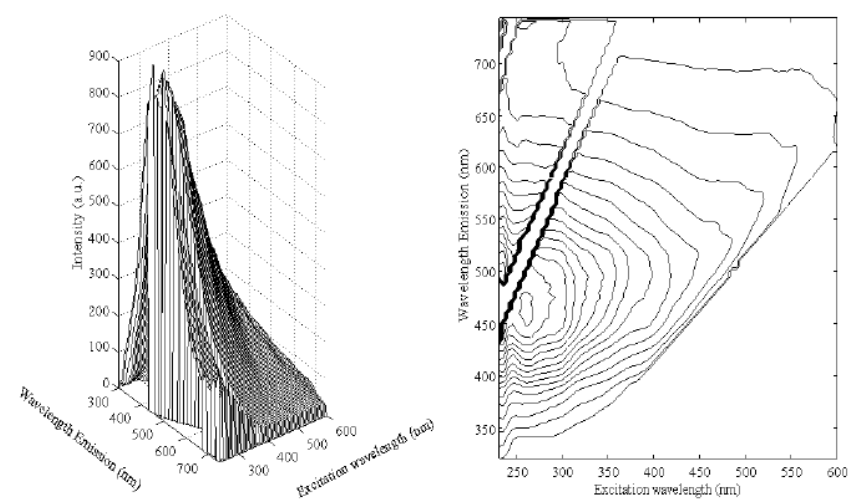

Figure 14: Total Fluorescence spectra of a crude oil sample ${ }^{51}$

There are three methods of analysing the sample. The first is to use Total Fluorescence Spectroscopy (TFS), where the sample it hit with one wavelength of electromagnetic radiation and all emitted wavelengths are measured. This process is repeated for different excitation wavelengths until a full profile is created. The data is presented as a 3D plot of excitation wavelength against emission wavelength with fluorescence intensity as the z-axis or as a $2 \mathrm{D}$ contour plot, as shown in Figure 14. The main disadvantage is that Raman and Rayleigh scattering of the excitation light can cause false signal $^{51}$. The excitation light wavelength is basically reflected and then detected by the spectrometer, giving an inaccurate emission spectrum. It is necessary to remove these as shown in 2D contour diagram in Figure 14.

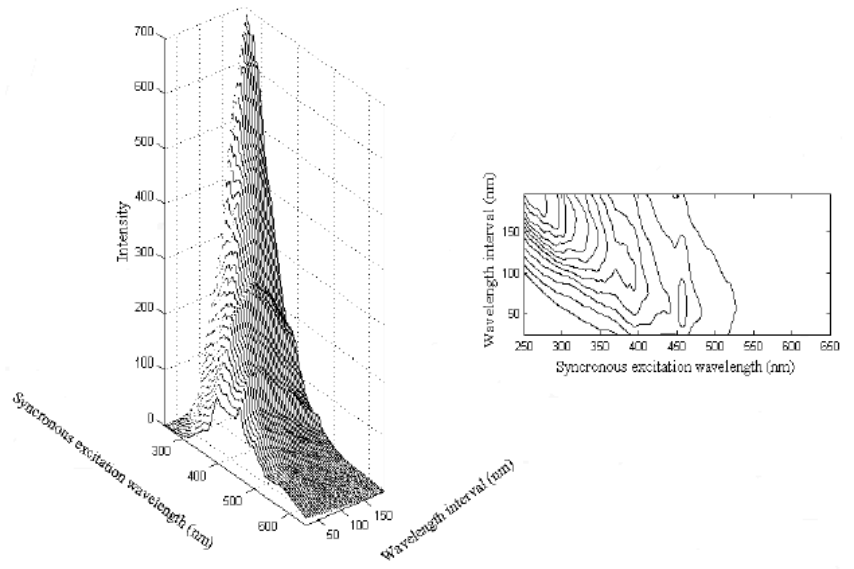

Figure 15: Synchronous Fluorescence spectra of a crude oil sample ${ }^{51}$

The second method is Synchronous Fluorescence Spectroscopy (SFS). This combines two different methods of fluorescence spectroscopy into one analysis. The first is to use an emission spectrum where the sample is analysed by using a beam of monochromatic light and measuring the resulting emitted wavelengths. The second is to use an excitation spectrum where the sample is analysed by hitting the sample with different wavelengths of light and measuring the emission of a single wavelength of light. SFS combines these by setting an initial emission wavelength $\left(\lambda_{\text {exc }}\right)$ to bombard the sample and an initial excitation wavelength $\left(\lambda_{\mathrm{em}}\right)$, with $\Delta \lambda$ being the difference between $\lambda_{\text {exc }}$ and $\lambda_{\text {em }} . \Delta \lambda$ is varied after each bombardment and a similar 3D plot to TFS can be created. The main advantage of SFS is clearer spectra when compared to TFS due to the reduced effect of Raman and Rayleigh scattering. Figure 15 shows the spectra obtained from SFS.
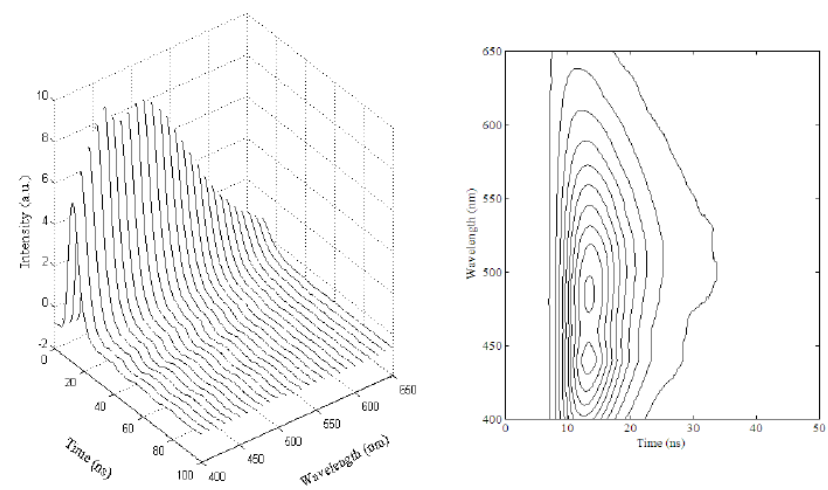

Figure 16: Time Resolved Fluorescence spectra of a crude oil sample ${ }^{51}$

The third method is Time Resolved Fluorescence Spectroscopy (TRFS) which measures the time a molecule remains excited for once it has absorbed a particular wavelength of light. A pulsed light source is used to excite the sample which will then emit different wavelengths of light at different times depending on the molecular structure. The data can be presented in a similar manner to TFS and SFS.

There is high potential to develop fluorescence spectroscopy as a sensor system. Experiments have already been conducted demonstrating its ability to analyse lubricants from oil sumps ${ }^{52}$. The system used UV light with $404 \mathrm{~nm}$ wavelength which was produced using a $\mathrm{GaN}$ laser diode and 
transmitted using optical fibre. Oil degradation was not classified by individual parameters, but an overall change in the condition over time. Similar studies have shown its use for identifying various different products of petrochemicals with similar composition to synthetic lubricants ${ }^{53}$.

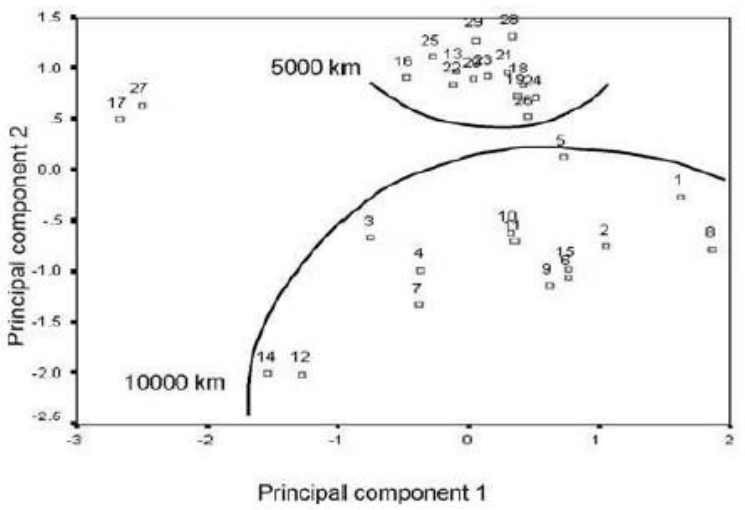

Figure 17: PCA of data from samples taken at $5000 \mathrm{~km}$ and $10,000 \mathrm{~km}^{52}$

In Figure 17, Principal Component Analysis (PCA) of samples is shown. This method is used to analyse multivariate data by changing a set of correlated variables into smaller components which are easier to interpret.

In addition, there have been recent developments of low cost integrated fluorescence sensors at University of Edinburgh $^{54}$. The main problem is achieving significant accuracy identifying key lubricant parameters. It is likely that fluorescence spectroscopy would not be used as an individual system but would be combined with other types of spectroscopy such as absorption as described by Mignani et $\mathrm{al}^{55}$.

\section{Electrical Conductance}

As the concentration of water varies in lubricants, its electrical resistance will also change. A gearbox lubricant has its capacitance tested for different percentages of water saturation. Once this has been established, an electrical probe is used to constantly measure the electrical of an oil supply channel and any change to the capacitance can be interpreted as a change in the water content.

The potential to develop electrical conductance as a sensor is high but is unlikely to provide any significant information about the oil. Several factors can affect the electrical conductance of lubricants. It may be useful to incorporate into a sensor system to augment data collection.

\section{POTENTIAL SOLUTIONS}

Out of the current technology that can identify parameters in gearbox lubricants, there are several that can potentially be adapted as cost-effective, compact and robust remote sensor for wind turbine gearboxes.

Fourier transform infra-red spectroscopy is one of the potential solutions. As mentioned previously, it has potential to detect various parameters such as TAN, TBN, oxidation and water content by analysing the amount of infra red radiation that is absorbed from an oil sample. The concept is relatively simple but difficult to adapt into a sensor. One method could be to use optical fibres to transmit the IR source to the desired analysis location ${ }^{56}$. There is a large range of commercial optical fibres used specifically to transmit IR radiation. Each is made of a specific material such as fluoride glass, single crystal glass fibres or chalcogenide glass ${ }^{57}$. When selecting optical fibre for radiation transmission, it is important to understand the wavelength attenuation spectrum. As shown in Figure 18.

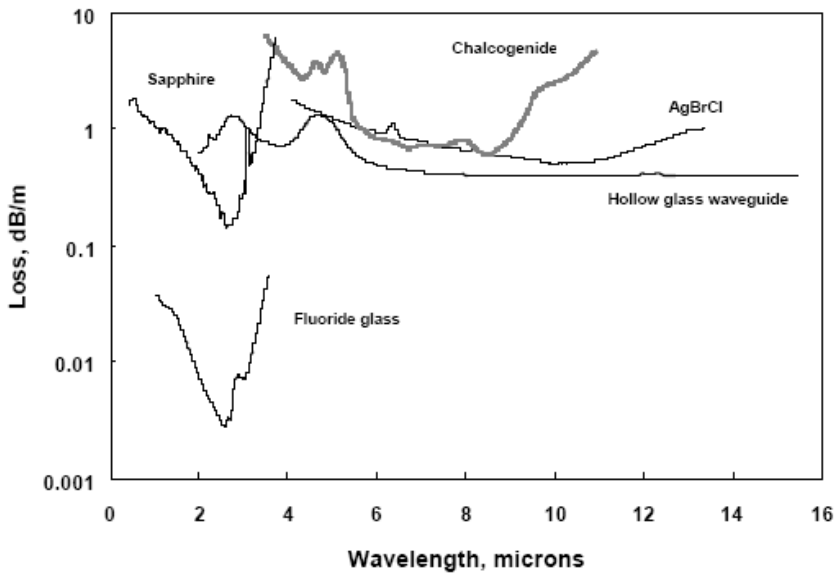

Figure 18: Attenuation spectra for different IR fibre optics ${ }^{57}$

With the presence of impurities and specific material properties, certain wavelengths of IR radiation are absorbed or scattered by the optical fibre. The importance of this effect depends on what is being analysed. As mentioned previously, there are certain compounds which need to be identified to assess the quality of the lubricant. Ideally optical fibre should transmit all wavelengths that would be absorbed by these compounds to allow accurate analysis. However in reality this may not be possible. As an example, carbonyl $(\mathrm{C}=\mathrm{O})$ strongly absorbs IR radiation between 1670 to $1820 \mathrm{~nm}^{39}$. If fluoride glass optical fibre was used, it would attenuate the signal at this waveband significantly. This would give a high evaluation of carbonyl groups, possibly leading to the false conclusion that oxidation levels are high. Fortunately there are a wide range of fibres with different wavelength attenuation ranges. It would be necessary to adopt several different types of fibre to ensure transmission of characteristic wavelengths. FTIR will only be able to be developed as an online sensor solution since the analysis process requires different groups of IR radiation to hit a sample. This means that the sample would have to be removed from its lubrication channel, hit with a series of wavelengths and then allowed to re-enter. The analysis itself takes only 0.25 to $1 \mathrm{~s}$ but is still long enough to prevent inline development. FTIR's main weakness is the inaccuracy in detecting water below $100 \mathrm{ppm}$. To improve upon this, there are two potential approaches. The first is to concentrate on improving absorption detection. This will be highly problematic as the water and oil both absorb a large range of IR radiation, giving ambiguous detection signals. The other solution is to develop a second sensor to compliment FTIR. This could be another absorption spectroscopic method as described by Mignani et $\mathrm{al}^{55}$. In this process, the information obtained from two or more different methods would be used in multivariate data processing to achieve higher accuracy ${ }^{58}$. 
PAS is another potential solution. The main reason for this is the extremely low water detection limits which have been demonstrated by Foster et $\mathrm{al}^{44}$. In this method, PAS was able to detect not only free water below $50 \mathrm{ppm}$ but also methanol and other groups which contained the hydroxyl group by using an excitation wavelength of $2930 \mathrm{~nm}$. The precise excitation wavelength depends on the type of oil that is being analysed and can be established by using FTIR spectroscopy. This is required as water has high absorbencies between 2700 and $3200 \mathrm{~nm}$, depending if the water is free, contained in an oil matrix and the type of lubricant. Each time, it is necessary to determine the approximate water absorbency wavelength which would then be used by PAS to excite the sample. Considering the advantages offered by PAS in detecting water and its potential relationship with FTIR, it is recommended that these two methods are used to complement each other in a CM system

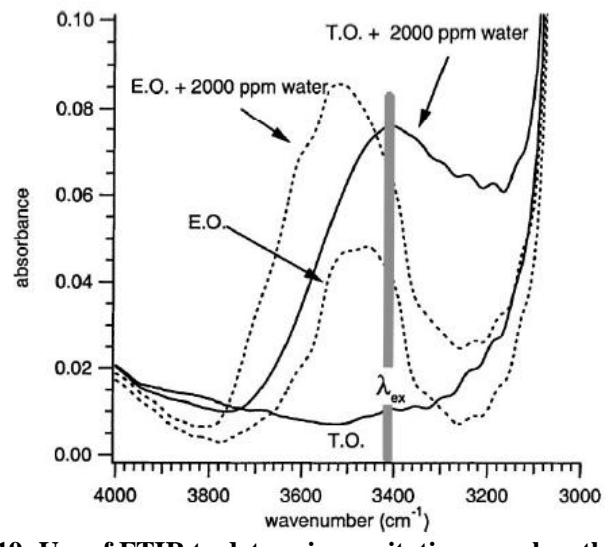

Figure 19: Use of FTIR to determine excitation wavelength for PAS sensor $^{44}$

Fluorescence spectroscopy (FS) is also a potential solution for lubricant quality analysis. The main advantages of FS as a sensing system include few spectral interferences and a wide analytical range ${ }^{59}$. This means that signals generally are representative of the presence of a compound rather than scattering or another anomaly. Changes in oil quality have currently been limited to assessing differences between emission spectra rather than individual characteristics, as shown in Figure 20. Whilst this data would not be particularly useful for wind turbine gearbox analysis, it can be used in conjunction with other sensors such as FTIR and PAS. Developing FS as a sensor is also possible. As demonstrated by Liang et al at the University of Manchester, it is possible to use FS as a small online sensor that utilises detailed data analysis techniques to establish the condition of engine oil ${ }^{52}$.

The main disadvantage has been insufficient excitation of the sample, leading to low fluorescence emissions and poor detection $^{52}$. It is recommended that FS is used as part of any oil analysis system due to the potential for miniaturisation and multivariate data analysis. In addition, FS may be used in identification of certain particulates suspended in lubricating oil.

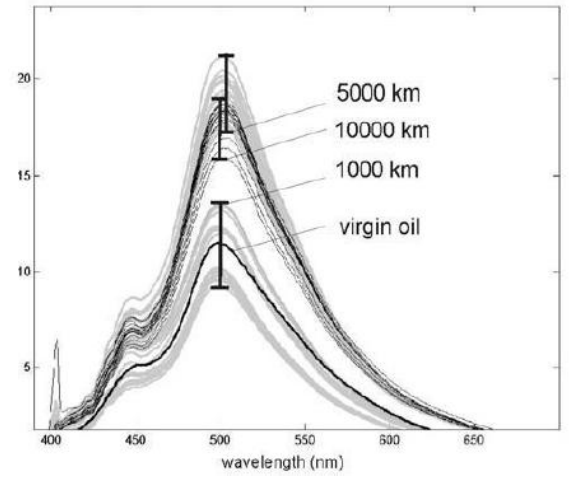

Figure 20: Fluorescence spectra from oil samples at different mileages ${ }^{52}$

Finally the last technology that is suitable for a gearbox CM system is solid state viscometers (SSV's). The main reason for its inclusion is the ability to measures viscosity directly. FTIR, PAS and FS cannot determine viscosity, although they may be able to give indications on the potential viscosity state. However any value obtained is likely to be inaccurate and so it not recommended.

\section{Particulate analysis}

\section{PHYSICS AND CHEMISTRY OF PARTICLUATES}

\section{A. Source and Composition}

Particulates suspended in lubricating oil originate from a variety of sources. In terms of a wind turbine gearbox, the vast majority are wear particles which have become detached from different gearbox components. Since there are no combustion engines, relatively few other particle contaminations such as soot are found within the oils. The surrounding environment may have an effect on additional contaminants.

\begin{tabular}{l|l}
\hline Component & Element \\
\hline Oil Pump & $\begin{array}{l}\text { Aluminium, Chromium, } \\
\text { Copper, Iron, Nickel } \\
\text { Chromium, Iron }\end{array}$ \\
Turbine Shaft & $\begin{array}{l}\text { Chromium, Iron, Nickel, } \\
\text { Molybdenum } \\
\text { Gears }\end{array}$ \\
Chromium, Iron, Nickel, \\
Titanium, Molybdenum \\
Chromium, Iron, Nickel, \\
Support Structure & $\begin{array}{l}\text { Mitanium }, \text { Magnesium, Iron } \\
\text { Magnesium, Iron }\end{array}$ \\
Gearbox & Copper, Silver \\
Bearing Cages & Molybdenum \\
Seals & Silver \\
Plated Materials &
\end{tabular}

Table 1: Table of gearbox components and their composition

In desert regions, small dust particles and silica may be present in the atmosphere and can enter the nacelle and gearbox. In an offshore area, the main additional contaminant is salt and a significant increase in moisture present in the atmosphere. Wear composition depends on the original component. A summary of the elements that are likely to be liberated from certain gearbox components is shown in Table 
1. By analysing the elemental composition of the particulates, it is possible to identify their potential source.

\section{B. Type of Wear}

Wear particles can also indicate the degree and type of damage that is being experienced by different gearbox components. The size and shape of particles are dependent on the type of erosion they have experienced whilst the number can signify the degree of damage that has occurred.

\section{1) Rubbing Wear}

Rubbing wear particles are generated by sliding contact surfaces. The particles are usually in the order of 5 to 15 microns in length, 1 micron in thickness and shaped like platelets. The wear surface would have a similar appearance to the original state with little changes to the texture. Whilst rubbing wear is undesirable and should require monitoring, it is usually an unavoidable form of normal operation ${ }^{60}$. Figure 21 shows rubbing wear particles from a scanning electron microscope.

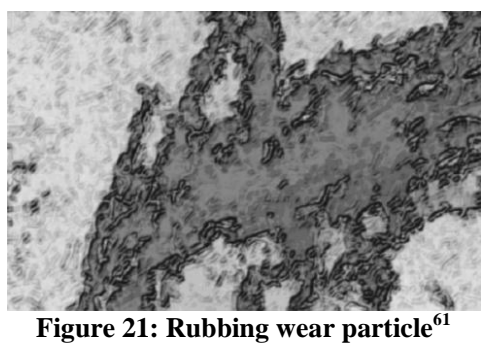

\section{2) Cutting Wear}

Figure 22 shows cutting Cutting wear particles occur when the surface of one component penetrates another. This can occur when a harder component becomes improperly aligned or develops a crack that disrupts its normal surface. This component then starts to penetrate a relatively softer surface. Since the force is concentrated on a smaller area, the particles are usually in the order of 25 to 100 microns long, 1 to 5 microns wide and have a coarse appearance. These particles may also occur if hard particles are suspended in the lubricant and begin to act as an abrasive between two different surfaces. In this case, the size of the wear particles depends on the size and shape of the contaminant. Cutting wear particles are not common in a machine that is operating correctly, therefore if such particles are found, it is highly likely that there is a problem. By analysing the size, shape and material composition, the source may be accurately identified (e.g component misaligned as opposed to abrasive particle contamination). Figure 22 shows cutting wear particles.

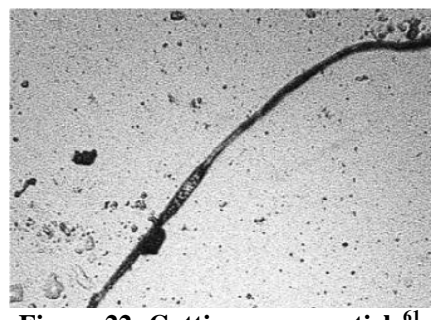

Figure 22: Cutting wear particle ${ }^{61}$

\section{3) Spherical Particles}

Spherical particles are normally created due to rolling contact fatigue wear and so are often associated with bearing wear. However they can also be a result of cavitation erosion and abrasive wear so require detailed analysis. In terms of bearing fatigue they are often a good indicator of future problems as they are usually generated before spalling occurs. The size of the particles can indicate the source with rolling fatigue producing particles in the order of 5 microns. Other types of wear usually generate spherical particles in the order of 10 microns $^{60}$. Figure 23 shows 2 spherical particles under a scanning electron microscope.

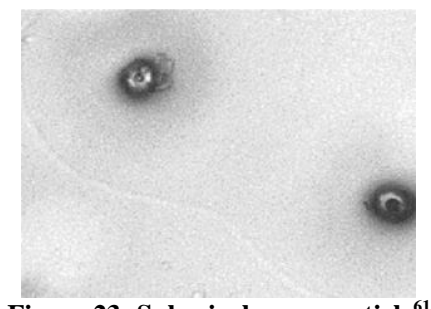

Figure 23: Spherical wear particle $^{61}$

\section{4) Severe Sliding}

Severe sliding wear particles are generated by two surfaces in contact under considerable force moving with different relative motions. Due to the force and variations in the surface, particles are liberated in the order of 15 microns or greater and may have a length to thickness ratio of $5: 1$ to $30: 1$, resulting in long, thin particles. As indicated by the name, the presence of these particles usually represents unusual or extreme loading conditions on components. This causes two surfaces to penetrate the lubrication film between them. Any detection of these particles would be of great concern.

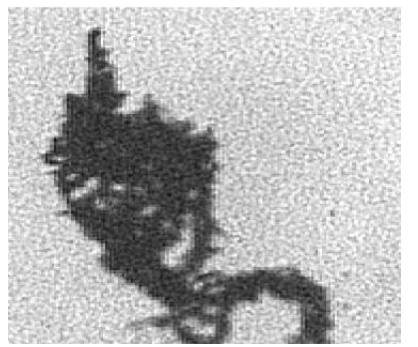

Figure 24: Severe sliding wear particle ${ }^{61}$

\section{5) Bear Wear Particles}

There are two types of bear wear particles that represent different wear conditions:

\section{a) Fatigue Spall Particles}

When a crack begins to develop, liberation of particles occur near to the initiation point of the crack. The size can vary as well as the shape but are generally less than 100 microns with a length to thickness ratio close to 10:1. This results in flat particles with a smooth surface and irregular circumference.

\section{b) Laminar Particles}

Laminar particles can occur when wear particles move through a rolling contact such as a bearing. Their presence normally indicates that a significant level of fatigue spalling is 
beginning to occur. The length normally varies between 20 and 60 microns with a length to thickness ratio of 30:1. In addition, many holes appear on the flat surface due to the forces exerted in the rolling contact. Since they begin to appear in large quantities with fatigue spalling, this can be an indicator of the degree of cracks in the rolling contact.

\section{6) Gear Wear}

Gears produce two distinctive types of wear that can indicate their condition:

\section{a) Pitch Line Fatigue Particles}

These particles are caused by the mechanisms of gear teeth interacting with each other. When two gear teeth come in contact, there are three key elements to understand why certain types of wear occur. Figure 25 shows the stages of teeth contact. The initial stage is contact where the teeth surfaces first come in contact. At this point, the teeth are sliding against each other due to the shape of the involute gear profile, resulting in sliding wear. If any abrasive material is present, it will also cause wear.

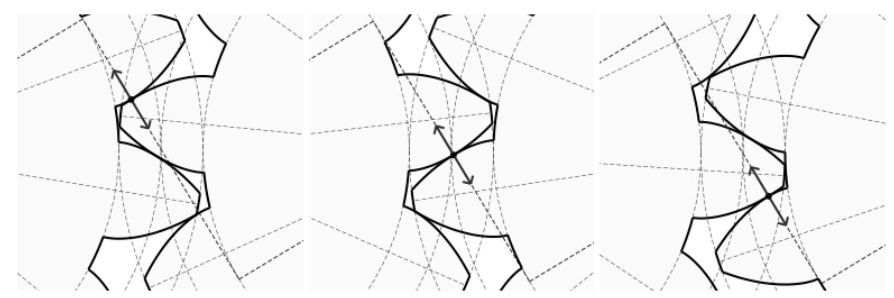

Figure 25: Moving of contact point along the pressure line (shown by movement of arrow

The middle stage is when the point of contact has reached the pitch point. At this stage the minimum amount of teeth are in rolling contact with each other and also experience the maximum pressure. Wear particles associated with type of contact are generated and also increased spalling. The last stage consists of more sliding, again due to the shape of the gear teeth. When new gearboxes are first run, there is a high degree of pitch line fatigue particles due to imperfections in the design and manufacture of gear teeth. However once gearboxes have been run in and this type of wear is seen, it can indicate teeth damage. The particle size is dependent of the gear size but usually have length to thickness ratios ranging $4: 1$ to $10: 1$ and have irregular shapes. Since a gear tooth can be viewed as a cantilever with a force being applied at varying points along its length. The tensile forces experienced by the tooth can cause micro cracks to develop and propagate, resulting in the thicker 4:1 ratio particles.

\section{b) Scuffing/Scoring Particles}

Scuffing particles normally develop due to high loads or increased speed that causes the teeth to break the lubrication film. Abrasive wear starts to occur, generating small, rough surfaced particles that are distinctive from other types of wear. Other indicators include striations on the surface due to sliding contact. Since scuffing involves greater amounts of friction, there is usually increased heat when they are generated, allowing greater oxide formation. This can aid identification due to the colour change that usually occurs in oxidised metals.

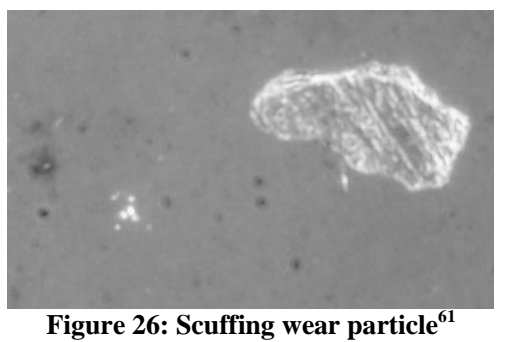

\section{Number of Particles}

Since component erosion will inevitably occur within a gearbox, the quantity of particles present in an oil channel is obviously a critical area to monitor. The main problem associated with this parameter is the orientation and shape of the particles.

\section{CURRENT TECHNOLOGIES}

\section{A. Scanning Electron Microscope (SEM)}

SEM analyses materials by hitting the sample with a beam of high energy electrons. This causes various different types of signals: back scattered electrons (BSE's), secondary electrons, x-rays, light and transmitted electrons. These signals can be interpreted in different manners to allow information about the chemical composition and shape of the sample to be determined. The types of signals that are produced can be divided into those that give information about the material composition and those which can be used to create an image of the material surface. The sample itself must be electrically conductive as this will prevent electrons from building up at the surface and disrupting scattering ${ }^{62}$. Standard SEM requires the sample to be contained within a vacuum as any presence of gaseous substances can disrupt the beam of electrons. This poses problems for samples that contain water and some oils as these would need to be dried. Environmental SEM (ESEM) allows samples to be prepared in a gaseous environment (i.e. not a vacuum), enabling samples to contain water and oil. The types of liquids that are allowed vary with the pressure inside the sampling region. Many modern ESEM allow variable pressure so that fluid samples may be analysed ${ }^{62}$. The disadvantage with this system is that more complex algorithms are required to compensate for the presence of gas, leading to longer analysis.

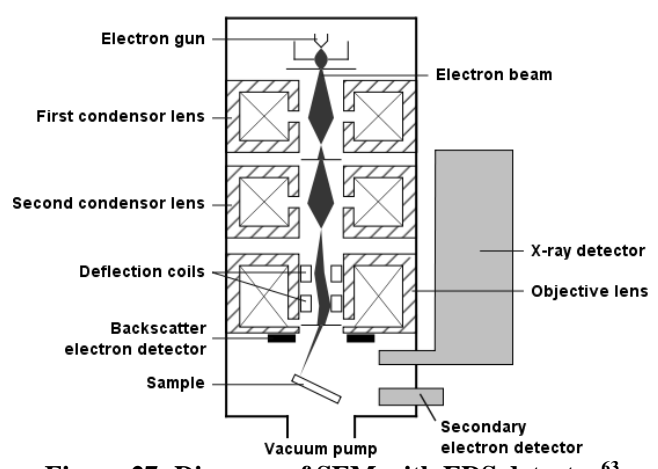

Figure 27: Diagram of SEM with EDS detector ${ }^{63}$ 
For surface imaging, secondary electrons are analysed. These are the original electrons which are present in the sample before the beam of high energy electrons hits. Due to the presence of extra higher energy electrons, the original electrons are displaced and will be emitted in a pattern related to the surface of the sample. An Everhart-Thornley detector is used to identify these secondary electrons which give signals that can be interpreted by software. The SEM scans in a raster pattern at high speed, allowing a highly detailed image to be created. The resolution and magnification of these images varies greatly between each type of machine but generally ranges from $10 \mathrm{~nm}$ to $100 \mathrm{~nm}$ with 10 to $500,000 \mathrm{x}$ magnification. To put in context, if a square wear particle in the order of $20 \times 20 \mu \mathrm{m}$ (microns) is magnified $10,000 \mathrm{x}$ by SEM, an image $20 \times 20 \mathrm{~cm}$ with a resolution of $15 \mathrm{~nm}$ could be displayed on screen. This could allow analysis of the type of wear occurring, for example shear or abrasion. Small personal SEM's (PSEM's) that are of similar size to laser printers can have the capability of 10 to $24,000 x$ magnification with resolution of $30 \mathrm{~nm}^{62}$. In terms of imaging, SEM is unparalleled for accuracy even when compared to laser imaging.

For composition analysis, there are two signals which can be used: BSE's and x-rays. BSE's are electrons from the beam which are deflected. The intensity at which this deflection occurs is proportional to the atomic number of the specimen. If the sample has a high atomic number (i.e. a large number of protons), the electrons will encounter a strong resistance to their negative charge which results in a strong repelling force. The BSE's are detected with sensors similar to the Everhart-Thornley device but positioned above the sample in concentric rings to ensure maximum capture. Since the intensity of the BSE's depends on the atomic number, the image produced will also indicate the material that is being analysed. In order to identify the sample's composition, image analysis software is now required. Generally a grey scale image will be produced which darker greys indicating higher atomic numbers.

$\mathrm{X}$-rays that are emitted from the sample after being hit by the high energy electrons can also be analysed. Each material and element has its own unique characteristic $\mathrm{x}$-ray which can be used to identify the sample in a process known as Energy Dispersive X-Ray Spectroscopy (EDS). When compared with BSE analysis EDS provides the most accurate results due to the uniqueness of the $\mathrm{x}$-ray signature whilst taking slightly longer ${ }^{62}$. However, EDS has to be considered a separate system from SEM as it can actually be applied on its own. All it requires to carry out spectroscopic analysis are characteristic $\mathrm{x}$-rays which are conveniently produced as a result of SEM bombardment. Many materials laboratories will only use EDS if the actual image is unimportant, using an $\mathrm{x}$-ray exciter to produce the required signals.

The price of a new SEM varies between manufacturers and specifications. For a device with laboratory grade accuracy, the price varies from $£ 100,000$ to $£ 200,000^{64}$. However, recently there have been developments in PSEM devices for small scale laboratories and industrial use. These devices do not include EDS and are generally used for their imaging capabilities, with some including BSE detectors for material analysis. One such device produced by FEI is the Phenom SEM which costs $£ 45,000$.

There is low potential to develop SEM as an online or inline gearbox oil sensor. It is clear that a system that can identify materials and elements which such accuracy and the ability to create images for wear and damage analysis would be a great asset to CM. However the cost of the equipment and the problems in integrating SEM as a functional sensor are too great to justify it as a candidate.

\section{B. Ferrography}

Traditional ferrography is a process that separates magnetic and non-magnetic particles from oil and then uses an optical sensor to analyse them. The first stage is to create slides called ferrograms (see Figure 28) for observation. The oil sample is diluted and allowed to flow down the ferrogram that is at an angle and has a magnetic cylinder underneath. The angle means that the magnetic field experienced is weaker at the start and stronger at the end. This causes larger ferrous particles to deposit at the start and smaller ferrous particles at the end.

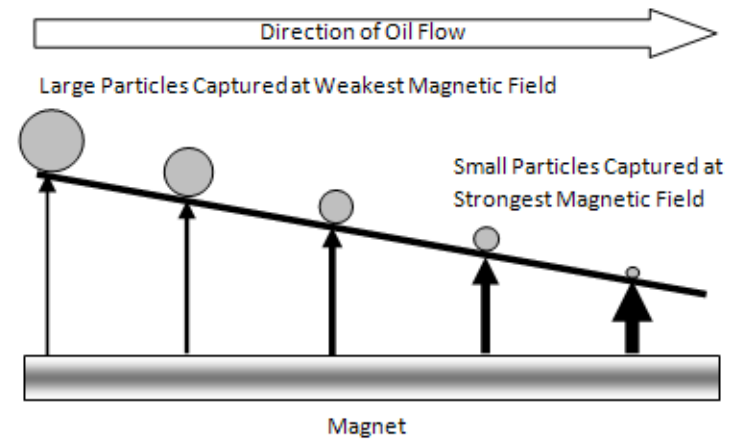

Figure 28: Operation of a ferrogram

Non-ferrous particles are deposited on the slide at locations depending on the concentrations of ferrous particles. If there were no ferrous particles in the sample, relatively few nonferrous particles would be captured in the ferrogram despite high concentrations in the sample. The slide is then washed to remove any lubricant and is ready for analysis using a bichromatic microscope. A reflecting red light source is situated above the sample and a green transmitting light source is situated below. A digital camera is used to take images that can then be classified. The final stage is to heat the slide to $320^{\circ} \mathrm{C}$ to distinguish between different particle types.

The categories of particles used by technicians are summarised in Table 2. In addition, the size and shape of particles can also be classified.

\begin{tabular}{l|l}
\hline Non-Ferrous & Ferrous \\
\hline White Nonferrous Particles & High Alloy Steel \\
Copper Particles & Low Alloy Steel \\
Babbitt Particles & Dark Metallic Oxides \\
Contaminants & Cast Iron \\
Fibres & Rust (Iron Oxides) \\
\hline
\end{tabular}

Table 2: Categories for non-ferrous and ferrous particles 
There is high potential to develop ferrography as a sensor. Online ferrographs have been created recently which use optical image processing in order to identify particles ${ }^{65,66}$, removing the need for an analyst. Currently accuracy and reliability depend on many different factors such as the flow rate of oil, the magnetic field strength and the distribution patterns of deposited particles. Despite this, the research is promising and also demonstrates the ability to miniaturise the technology, a key requirement for wind turbine nacelles.

\section{Atomic Spectroscopy (AS)}

Atomic spectroscopy is a broad area that covers many different types of spectroscopic analysis. Several of these techniques are currently used to identify metals in lubricant oil in laboratory tests. However samples often require preparation to be compatible with the instrumentation; complex hydrocarbons with relatively high viscosities generally cannot be analysed directly. Methods include dissolving lubricants in acid to mineralise the oil matrix and allow metals to form aqueous solutions. This allows far easier calibration for the particular AS method. However it is clear that these complex preparations will be unsuitable for a robust online system which will have to operate continuously for periods in the order of years.

\section{$M S)$}

1) Inductively Coupled Plasma Mass Spectroscopy (ICP

ICP MS converts a sample into an ionic plasma by extreme heating. In this state, ions can be displaced by a magnetic field due to the overall positive charge. Since ions with larger atomic numbers will have a greater positive charge, the value of displacement will be characteristic of the atom ${ }^{67}$. By using mass spectrometry to distinguish different elements, it is possible to identify the composition of material wear ${ }^{68}$. However ICP MS is unsuitable for development as an online/inline sensor. It requires expensive and large equipment such as the mass spectrometer and requires sample preparation so would be unfeasible as a solution ${ }^{69}$.

\section{2) Flame Atomic Absorption Spectroscopy (FAAS)}

FAAS uses a flame to atomise an oil sample which is then scanned with different wavelengths of light. The values of absorbed wavelength correspond to particular elements similar to other absorption spectroscopic methods. Generally samples must be converted into an emulsion to reduce the organic elements of the sample (hydrocarbons) ${ }^{70}$, although direct introduction into the flame atomiser is possible ${ }^{69}$. The main problem with FAAS is the process of atomising and destroying the sample. Lubricant supplies are limited in wind turbine so destructive sampling methods are not recommended.

\section{3) Optical Emission Spectroscopy (OES)}

OES relies on the excitation of the sample by flame, inductively coupled plasma or by arc discharge to emit characteristic wavelengths of light. Inductively coupled plasma optical emission spectroscopy (ICP OES) is the most widely used method due to its reliability and accuracy ${ }^{69}$. The sample generally requires dilution in an organic solvent before it can be converted into a plasma ${ }^{71}$. An online system using
ICP OES has been demonstrated with detection limits of 10 $\mu \mathrm{m}^{72}$. However the system still requires sample dilution and large expensive equipment.

\section{4) Laser-Induced Breakdown Spectroscopy (LIBS)}

LIBS is a branch of atomic emission spectroscopy that uses a high powered laser to cause emissions of light. When the laser beam contacts the sample, a small amount of the material at the surface detaches and becomes plasma with an incredibly high temperature. The high thermal energy causes the material to break down into individual elements and ions. When the sample cools, it emits characteristic wavelengths which can be detected by a spectrometer. Nd:YAG lasers with a wavelength of $1064 \mathrm{~nm}$ are generally used to create the plasma $^{73}$. LIBS identifies particles in the same manner as other emission spectroscopic technologies. The main difference is the formation of the plasma layer. By creating this, the state of the material does not matter (solid liquid, gas) as all can be converted to plasma. There is low potential to develop LIBS as an online solution due to the cost.

\section{5) Fluorescence Spectroscopy (FS)}

FS used extensively to identify iron, molybdenum, and copper wear particles in jet engine oils ${ }^{74}$. According to Aucélio et al, detection limits in the order of $\mu \mathrm{g} / \mathrm{g}$ were of these elements ${ }^{69}$. However determining nickel and chromium are far less accurate due to band structuring and continuous background $^{75}$. Sample preparation is not required but atomisation is, usually by means of a graphite rod. Only small samples are required to take accurate measurements, therefore the system may be considered as non-destructive. There is high potential to develop FS as an online particulate sensor, especially as the system is effective at assessing oil quality parameters.

\section{Particle Counters}

Particles counters are to quantify the amount of wear that is present in a lubrication channel. This is achieved by measuring different physicals features of the particulates. One standard method is to use a laser beam with a uniform intensity to pass light through an oil channel ${ }^{76}$. This light is detected at the opposite side by a photo diode that gives a variable voltage signal (see Figure 29). If a particle passes between the laser and the diode, the value of light falls, resulting in a voltage drop. This means the voltage can be correlated to the size of the particle. For a given lubrication channel, it is possible that there will be many hundreds of particles passing at a certain point, spread across the cross sectional area. In order to detect all particles, the channel must be reduced or several sensors used. In most cases, the channel is reduced by attaching a tributary conduit to the lubrication channel which will remove oil continuously and return it at a later point. This tributary may be of a small diameter to ease particle identification. 


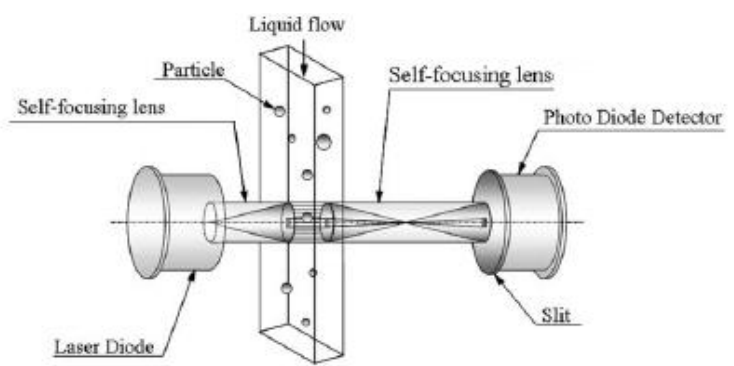

Figure 29: Operation of a particle counter ${ }^{76}$

An alternative method is to use a filter and measure the blockage as a function of flow or pressure through a channel. The filter has uniform porosity which is designed to remove large particles initially. Smaller particles begin to get trapped once the local porosity has been reduced by larger particles until only the smallest can pass. Either the change in flow through the channel is measured or the increase in pressure at the filter. From this change, the size of particles can be estimated at different stages of the machines operational life.

\section{Flow Change of Porous Particle Counter}

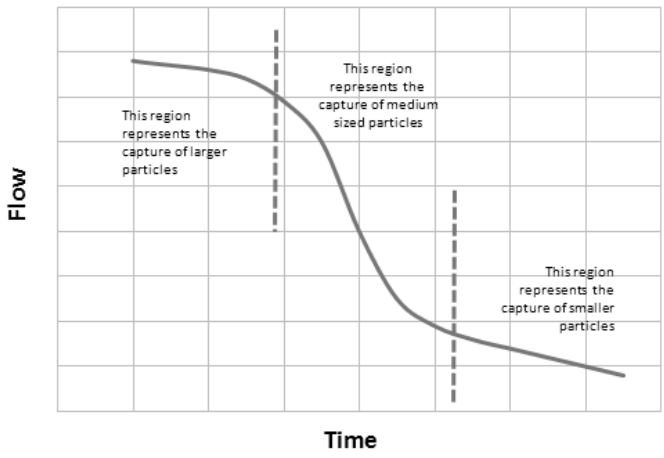

Figure 30: Change in flow rate of a channel with increasing blockages ${ }^{77}$

Optical counters identify the size and shape of particles by analysing the voltage pulses that are generated by the photo diode. The shape will affect both the duration of the pulse and the amplitude of the voltage spike. A relationship between the voltage spike and the area must be calibrated before accurate measurements can be taken. Estimating the thickness of the particles is necessary as the system can only identify particles in $2 \mathrm{D}$. Another relationship between the diameter and the thickness must also be developed for the particles that are expected to be found in the machine. The machine cannot be used to identify the material composition; it is only used to determine the number of particles and their size present in a lubricant. Additional equipment would be needed to analyse the elemental composition.

Filter counters do not identify size and shape accurately and instead give a general indication of the size of particles that are being collected. The shape of the flow rate against time is analysed to determine the time when particles of certain diameters are liberated. Its accuracy is low since there are a variety of scenarios that could give false interpretations of the wear condition in a lubrication channel.

There is significant potential to develop optical particle counters as an online system for wind turbine gearbox analysis. There is currently a large range of commercial particle counters designed for this purpose ${ }^{78}$. In addition, several research and industrial groups are conducting research into improving the accuracy of these devices. The equipment required for the sensor is low cost and also can be miniaturised for the purposes of the wind energy industry. Future research should consist of integrating the sensor with technology that identifies the composition of the particles to allow greater understanding of the gearbox's state.

\section{E. Radioactive Tagging}

In medicine, it is often necessary to trace blood flows to the heart, spread of cancerous cells and scan organs to a higher degree than conventional methods ${ }^{79}$. To achieve this, radioactive tracers are introduced into the body. These tracers usually consist of an isotope of a particular element that is unstable. Due to radioactive decay, these isotopes emit different particles and radiation which can be detected by a Geiger-Müller tube. Despite being an uncommon technique outside of medicine, the principle could be applied to gearboxes. Certain components such as the bearings could be 'tagged', by mildly irradiating the surface, creating small numbers of isotopes. When these are librated due to wear, they will travel in the lubrication channel and be detected. The signal will depend on the number of particles liberated, hence indicating the state of wear.

Radioactive tagging could be used to both quantify the amount of wear and the material type through indirect means. If the component is irradiated so only a particular element becomes an isotope, such as iron, then the presence of radioactive decay can be attributed to that element. The quantity would be established by measuring the intensity of radiation.

There is moderate potential to develop radioactive tagging as a sensor. The main advantages are the highly specific detection method. However, the method would require components to be irradiated during the manufacturing process. Also decommissioning any old wind turbines would have added complications due to the trace levels of radiation.

\section{F. Electromagnetic Detection (EMD)}

There are a variety of EMD methods which are used in detecting metallic wear and other parameters in oil in lubricating oils. Currently, it is the most popular technique for online/inline lubrication condition monitoring in the vehicle and manufacturing industries

\section{1) Induction Factor}

Induction involves measuring the change of a magnetic flux field as particles enter. Typically, an inductive coil is placed around a tube or container to create a magnetic field through which the fluid passes. By using electronic circuitry and software, it is possible to neglect signals from air bubbles. Induction sensors can also differentiate between ferrous and non-ferrous debris. Metallic particles have higher conductivity than oil, resulting in increases in current proportional to the quantity and type of material. Currently, induction sensors are commercially available from manufacturers such as MACOM $^{\mathrm{TM}} 80$. Miniaturisation of the technology has also been demonstrated ${ }^{81}$. 
2) Dielectric Constant (DEC)

A dielectric is an insulator and the constant is the rate of electric flux density produced in a material to the value in free space provided by the same electric field strength. This technique is able to detect when a change has occurred in the oil. Wear debris can be detected in this manner but only in a generally sense: material composition and wear type cannot be determined to any degree of accuracy. Changes in chemical composition can affect the DEC, further diminishing its wear analysis capabilities. However due to the cheap, robust nature of the technology, it is often used to monitor the general condition of lubrication oil ${ }^{82}$.

\section{3) Dielectric Loss Factor (DELF)}

DLF (or TanDelta) increases strongly with polar contaminants such as water, glycol and oxidation products. Metallic debris and soot also increase the tandelta. It also has a greater dynamic range when compared to the dielectric constant and is more sensitive to the oil condition. It is currently used in vehicle lubrication condition monitoring to indicate abnormal conditions.

\section{4) Magnetic Flux Constant (MFC)}

The concentration of ferromagnetic particles is estimated by means of a fixed magnetic field. The field collects the particles and the field is likewise modified by the presence of the particles. This change in the magnetic flux is monitored and can be converted to the ferromagnetic particle concentration by means of an algorithm. Other elements such as nickel and molybdenum cannot be detected potential use of MFC as a CM sensor.

\section{5) Electric Filters}

Ferromagnetic particles are attracted to an electric grid or plates which serve as opposing electrodes. Current flow between the electrodes signals the presence and general concentration of conductive magnetic particles. Depending on the design, the spacing of the grid/plates and a time-sequence can be used to estimate particle size and concentration of wear debris in the oil. This technology is commercially available from HVDACLab and it used in the wind turbine industry ${ }^{80}$.

\section{POTENTIAL SOLUTIONS}

Currently there is no single technology which can accurately count, quantify, categorise and identify elemental composition of particles suspended in oil as part of a low cost, online/inline system. However there is a wide range of technologies which can fulfil some of these criteria and there is significant potential for integrating them into one system.

Since the elemental composition of the gearbox is known, a list of potential particulates can be established. Additionally, other contaminants such as silica or dirt are unlikely due to the high elevation of the wind turbine nacelle and the environments wind farms are built. This allows sensors to be developed that can selectively identify certain elements and compounds such as iron, nickel, chromium and molybdenum. There are also several types of effect that can be observed to identify particles. Each element or molecule could have a laser diode emitting light corresponding to its characteristic wavelength, allowing selective identification. Emission of certain wavelengths could be observed, using a light source and detector calibrated to identify unique emissions. A related method of identification is to observe any scattering effects that are displayed by different chemicals ${ }^{83}$. Sensors can be positioned at different angles around an oil channel to detect wavelengths of light that have been reflected by particulates. The angle and intensity at which the reflection occurs can be related to a particular material.

An optimal solution would be to use a combination of these techniques as it is unlikely that one would have the required accuracy. Data collected from one solution would be augmented from another source. Identification of particles will not depend solely on the sensing capabilities, but also on the statistical methods which will be used to interpret the information gathers by sensing devices ${ }^{84}$. Data collected from a cheap sensor with relatively inaccurate identification capabilities could be enhanced with data collected from a similar sensor that observes a different effect. By employing sensors in this manner, there is great potential for achieving an accurate, low cost solution to particulate identification in oil.

Fluorescence spectroscopy (FS) is an ideal solution as it can be adapted into an optical fibre sensor making it cheap and robust. Since FS is already highly recommended to analyse oil quality, it would be relatively simple to vary wavebands for particulate identification. Unfortunately exact spectroscopic analysis of samples is unlikely due to the lack of sample preparation and atomisation. However another approach may be taken. Spectra obtained from oil samples with known quantities of metallic wear can be compared to measured spectra of gearbox lubricants. Data analysis techniques would then be used to establish relationships and correlations between different aspects of the spectra. Using this indirect method, it is possible to assess the current levels of metallic wear and future trends. This type of analysis may not have the desired accuracy as an independent system. Incorporation of other technologies would dramatically reduce the errors that are expected

Particle counters also have great potential as they are commercially available devices and have demonstrated reasonable accuracy in quantifying the amount of wear in lubricants.

\section{RECOMMENDATIONS}

Lubrication analysis of wind turbine gearboxes poses unique challenges for developing a robust condition monitoring system. The isolation of wind turbines, both onshore and offshore, and constraints prevent the use of many standard analysis techniques for reasons of cost, size and accuracy. It is highly probable that any CM system will require new research into adapting current technology into sensors that can fulfil the criteria. This report has reviewed the various technologies that are used or could be adapted for use in such a system. For oil quality analysis, it is recommended that a combination of Fluorescence Spectroscopy, Fourier Transform Infrared Spectroscopy, Solid State Viscometers and Photoacoustic Spectroscopy should be used with multivariate data processing. It is believed that a combination of smaller, less accurate sensors will yield adequate information to assess the current condition of the oil and the future trends. For analysing wear particles suspended 
in the oil, it is recommended that ferrography, particle counting, fluorescence spectroscopy and a simple electrical constant sensor are adopted. From reviewing the state of the current technology it is believed that all systems may be miniaturised and integrated into one system. Again considerable multivariate data analysis will then be necessary to evaluate the material composition, quantity and wear type. Similar systems are already under development which utilise multi-sensor techniques such as the Lube-Lab on-a-Chip from Purdue University. Radioactive tagging may also be a candidate for a CM system. There has currently been little research into the area.

\section{REFERENCES}

${ }^{1}$ European Wind Energy Association (EWEA), Wind Energy - The Facts, London, Earthscan, 2009.

${ }^{2}$ P. J. Tavner, G. J. W. van Bussel, F. Spinato, Machine and Converter Reliabilities in Wind Turbines, in Proc. 3rd IET International Conference on Power Electronics, Machines and Drives, Mar. 2006, pp. 127-130

3 B. McNiff, The Gearbox Reliability, in Proc. 2nd Sandia National Laboratories Wind Turbine Reliability Workshop, September 2007.

${ }^{4}$ C. Ensslin, M. Durstewitz, B. Hahn, B. Lange, K. Rohrig, German Wind Energy Report 2005. ISET, Kassel, 2005.

${ }^{5}$ T. Burton, D. Sharpe, N. Jenkins, E. Bossananyi, Wind Energy Handbook, Chichester, John Wiley and Sons Ltd, 2003.

${ }^{6}$ W. M. Needelman, M. A. Barris, G. L. LaVallee, Contamination Control for Wind Turbine Gearboxes, in Power Engineering, November 2009.

${ }^{7}$ National Grid, Round 3 Offshore Wind Farm Connection Study, accessed from: http://www.thecrownestate.co.uk/round3_connection_study.pdf, 2 on $1^{\text {st }}$ September 2010.

${ }^{8}$ C.J. Crabtree, Survey of Commercially Available Condition Monitoring Systems for Wind Turbines, Durham University, 2010.

${ }^{9}$ D. McMillan and G. W. Ault, Quantification of condition monitoring benefit for offshore wind turbines, Wind Engineering, vol. 31, no. 4, pp. 267-285, May 2007.

${ }^{10}$ Y. Zhan, V. Makis, A Robust Diagnostic Model for Gearboxes Subject to Vibration Monitoring, Journal of Sound and Vibration, Volume 290, Issues 35, 7 March 2006, Pages 928-955, ISSN 0022-460X.

${ }^{11}$ L. Gelman, R. Zimroz, J. Birkel, H. Leigh-Firbank, D. Simms, B. Waterland, G. Whitehurst, Adaptive Vibration Condition Monitoring Technology for Local Tooth Damage in Gearboxes, Insight: non-destructive testing and condition monitoring, Vol. 47 Iss. 8; Aug 2005 pp.461-464.

${ }^{12}$ D. J. Lekou, F. Mouzakis, A. Anastasopoulos, and D. Kourousis, Emerging Techniques for Health Monitoring of Wind Turbine Gearboxes and Bearings, Proc. EWEC 2009, Scientific Track - Operation and Maintenance, Marseille, France, March 16-19, 2009.

${ }^{13}$ L. A. Toms, Machinery Oil Analysis - Methods, Automation \& Benefits $3^{\text {rd }}$ Edition, STLE, Virginia Beach, 2008.

${ }^{14}$ C.J. Crabtree, Survey of Commercially Available Condition Monitoring Systems for Wind Turbines, Durham University, 2010.

${ }^{15}$ J. J. Christensen, C. Andersson, S. Gutt, Remote Condition Monitoring of Vestas Turbines, Technical Track - Operation \& Maintenance, Proc. EWEC 2009, Marseille, France, Mar. 16-19, 2009.

${ }^{16}$ Gear Foundation Course Notes, Version 2, September 2009, David Brown Gear Academy.

${ }_{17}$ M. J. Neale, Lubrication and Reliability Handbook, Bristol, J. W. Arrowsmith Ltd, 2001.

${ }^{18}$ D. P. Walsh, Oil Analysis 101, Orbit Vol.25 No.2, 2005

${ }^{19}$ D. Li, J. Sedman, D. L. García-González, F. R. van de Voort, Automated Acid Content Determination in Lubricants by FTIR Spectroscopy as an Alternative to Acid Number Determination, Journal of ASTM International, Vol. 6, No. 6 Paper ID JAI102110, accessed from www.astm.org on $10^{\text {th }}$ September 2010.

${ }^{20}$ D. D. Ebbing, S. D. Gammon, General Chemistry ( $9^{\text {th }}$ Edition), Houghton Mifflin Company, Boston, 2009.

${ }^{21}$ N. Gracia, S. Thomas, P. Bazin, L. Duponchel, F. Thibault-Starzyk, O. Lerasle, Combination of Mid-Infrared Spectroscopy and Chemometric Factorization Tools to Study the Oxidation of Lubricating Base Oils, In Press, Corrected Proof,
(http://www.sciencedirect.com/science/article/B6TFG-4Y29T0F-

2/2/c620179adf02754c306f1556cc40e51f) $31^{\text {st }}$ December 2009.

${ }^{22}$ C. J. Seeton, Viscosity-Temperature Correlation for Liquids, Tribology Letters, Volume 22, No.1, 67-78, 2006.

${ }^{23}$ D. S. Viswanath G Natarajan, Data Book on the Viscosity of Liquids, Hemisphere Pub. Corp, New York,1989.

${ }^{24}$ ASTM D2422 - 97(2007), Standard Classification of Industrial Fluid Lubricants by Viscosity System, ASTM International.

${ }^{25}$ L. R. Rudnick, Lubricant Additives, CRC Press, ,2009.

${ }^{26}$ R. M. Mortier, S. T. Orszulik, Chemistry and Technology of Lubricants $\left(2^{\text {nd }}\right.$ Edition), Blackie Academic and Professional, London, 1997.

${ }^{27}$ Z. Pawlak, Tribochemistry of Lubricating Oils, Elsevier, Amsterdam, 2003.

${ }^{28}$ Aqua Star - Karl Fischer Titration Basics, EMD Chemicals, 2010, accessed from: http://www.emdchemicals.com/ on $2^{\text {nd }}$ September 2010.

${ }^{29}$ G. Wieland, K. Fischer, Water Determination by Karl Fischer Titration, University of Michigan, Git Verlag, 1987.

${ }^{30}$ InTech Website, accessed from http://www.isa.org on $1^{\text {st }}$ September 2010

${ }^{31}$ Aqua Star - Karl Fischer Titration Basics, EMD Chemicals, 2010, accessed from: http://www.emdchemicals.com/ on $2^{\text {nd }}$ September 2010.

${ }^{32}$ G. Wieland, K. Fischer, Water Determination by Karl Fischer Titration, University of Michigan, Git Verlag, 1987.

${ }^{33}$ Aqua Star - Karl Fischer Titration Basics, EMD Chemicals, 2010, accessed from: http://www.emdchemicals.com/ on $2^{\text {nd }}$ September 2010.

34 Dexsil - Diagnostic Test for Water in Oil, accessed from http://www.dexsil.com/uploads/docs/dtr_22_01.pdf on $2^{\text {nd }}$ September 2010.

35 B. Stuart, Infrared Spectroscopy: Fundamentals and Applications, Chichester, John Wiley and Sons Ltd, 2004.

${ }^{36}$ C. Párkányi, Theoretical Organic Chemistry, Amsterdam, Elsevier Science, 1998.

37 B. Stuart, Infrared Spectroscopy: Fundamentals and Applications, Chichester, John Wiley and Sons Ltd, 2004.

38 Machinery fubrication, accessed from http://www.machinerylubrication.com on 9th September 2010.

39 I. Poljanšek, M. Krajnc, Characterization of Phenol-Formaldehyde Prepolymer Resins by In Line FT-IR Spectroscopy, Acta Chimica Slovenica, 2005, 52, 238-244

${ }^{40}$ L.A.Toms, Machinery Oil Analysis Methods, Automation and Benefits, $3^{\text {rd }}$ Edition, STLE, Virginia Beach, 2008.

${ }^{41}$ SpectroInc. QinetiQ North America, FluidScan $\mathrm{Q}^{1000}$, accessed from http://www.spectroinc.com/products-fluidscan.htm on August $25^{\text {th }} 2010$.

42 Encyclopaedia of Spectroscopy and Spectrometry (2 ${ }^{\text {nd }}$ Edition), "Photoacoustic Spectroscopy, Theory"

${ }^{43}$ Encyclopedia of Analytical Science ( $2^{\text {nd }}$ Edition), pages 174-180, 2005.

${ }^{44}$ N.S. Foster, J.E. Amonette, T. Autrey, J.T. Ho, Detection of Trace Levels of Water in Oil By Photoacoustic Spectroscopy, Sensors and Actuators B 77 (2001) 620-624

45 MICEPAS: Miniaturised Cell Enhanced Photoacoustic Spectroscopy (2009), accessed from http://www.micepas.basnet.by/ on August $10^{\text {th }} 2010$.

${ }^{46}$ S.L. Firebaugh, K.F. Jensen, M.A. Schmidt, Miniaturization and Integration of Photoacoustic Detection with a Microfabricated Chemical Reactor System, Journal of Microelectromechanical Systems, Vol. 10, No. 2, June 2001.

${ }^{47}$ G. W. Stachowiak, A. W. Batchelor, Engineering Tribology, Elsevier, Oxford, 2005.

${ }^{48}$ D. S. Viswanath, Viscosity of Liquids: Theory, Estimation, Experiment and Data, Springer, Dordrecht, 2007.

${ }^{49}$ D. Kereme, Solid State Viscometer for Real-Time, On-line and

In-line Oil Condition Monitoring, ChemOnline, 2005.

${ }_{50}$ J. R. Lakowicz, Topics in Fluorescence Spectroscopy Vol. 2 Principles, Plenum Press, New York, 1991.

${ }^{51}$ F. F. Sotelo, P. A. Pantoja, J. López-Gejo, G. A. C. Le Roux, F. H. Quina, C. A. O. Nascimento, Application of Fluorescence Spectroscopy for Spectral Discrimination of Crude Oil Samples, Brazilian Jouranl of Petroleum and Gas, v. 2, n. 2, p. 63-71, 2008.

${ }^{52}$ T. K. Liang, M. Friedrich, D. Lala, K. B. Ozanyan, Portable Fluorescence Sensor for On-line Monitoring of Lubricant Oils, Sensors, 2004. Proceedings of IEEE , vol., no., pp. 8- 11 vol.1, 24-27 October, 2004

${ }^{53}$ D. Patra, A. K. Misha, Total Synchronous Fluorescence Scan Spectra of Petroleum Products. Analytical and Bioanalytical Chemistry, v.373, p. 304309, 2002.

54 S. Smith, Sensor Activity in the Scottish Engineering Research Partnerships, University of Edinburgh, April 2008.

55 A. G. Mignani et al, Optical Fiber Spectroscopy for Measuring Quality Indicators of Lubricant Oils, Meas. Sci. Technol. 20 034011, 2009 
${ }^{56}$ J. A Harrington, Infrared Fibers and Their Applications, SPIE, Washington, 2004.

${ }^{57}$ J. A. Harrington, Infrared Fiber Optics, OSA Handbook, Vol III.

58 A. C. Olivieri, Analytical Advantages of Multivariate Data Processing, Anal. Chem. 2008, 80, 5713-5720

${ }^{59}$ L. H. J. Lajunen and P. Perämäki, Spectrochemical Analysis by Atomic Absorption and Emission ( $2^{\text {nd }}$ Edition), The Royal Society of Chemistry, Cambridge, 2004.

${ }^{60}$ B. K. N. Rao, Handbook of Condition Monitoring ( $1^{\text {st }}$ Edition), Elsevier Advanced Technology, Oxford, 1996.

${ }^{61}$ S. Ghosh, B. Sarkar, J. Saha, Wear Characterization by Fractal Mathematics for Quality Improvement of Machine, Journal of Quality in Maintenance Engineering, Vol 11, No. 4, accessed from http://www.emeraldinsight.com/journals.htm?articleid=1520151\&show $=$ html

${ }^{62}$ J. Goldstein, D. Newbury, D. Joy, C. Lyman, P. Echlin, E. Lifshin, L. Sawyer, J. Michael, Scanning Electron Microscopy and X-ray Microanalysis $\left(3^{\text {rd }}\right.$ Edition), Plenum Publishing Corporation, New York, 2003.

63 Scanning Electron Microscope, Purdue University, Department of Radiological and Environmental Management, accessed from http://www.purdue.edu/rem/rs/sem.htm, on $2^{\text {nd }}$ August 2010.

${ }^{64}$ Scanning Electron Microscopes, Popular Mechanics (2010), accessed from http://www.popularmechanics.com/technology/gadgets/4218957 on the $8^{\text {th }}$ August 2010.

${ }^{65}$ T.H. Wu, J.H. Mao, J.T. Wang, J.Y. Wu, Y.B. Xie , A New On-Line Visual Ferrograph, Tribology Transactions, (2009) 52(5), 623-631.

${ }^{66}$ N. K. Myshkin, L. V. Markova, M. S. Semenyuk, H. Kong, H. -G. Han, E. S. Yoon, Wear Monitoring Based on the Analysis of Lubricant Contamination by Optical Ferroanalyzer, Wear, Volume 255, Issues 7-12, 14th International Conference on Wear of Materials, August-September 2003, Pages 1270-1275, ISSN 0043-1648, DOI: 10.1016/S0043-1648(03)00175-3.

${ }^{67}$ C.J. Lord, Determination of Trace Metals in Crude Oil by Inductively Coupled Plasma Mass Spectrometry with Micro-emulsion Sample Introduction, Anal. Chem. 63 (1991), pp. 1594-1599.

${ }^{68}$ M.P. Escobar, B.W. Smith and J.D. Winefordner, Determination of Metalloorganic Species in Lubricating Oil by Electrothermal Vaporization Inductively Coupled Plasma Mass Spectrometry, Anal. Chim. Acta 320 (1996), pp. 11-17. ${ }^{69}$ Ricardo Q. Aucelio, Roseli Martins de Souza, Reinaldo Calixto de Campos, Norbert Miekeley, Carmem L. Porto da Silveira, The determination of trace metals in lubricating oils by atomic spectrometry, Spectrochimica Acta Part B: Atomic Spectroscopy, Volume 62, Issue 9, 9th Rio Symposium on Atomic Spectrometry, September 2007, Pages 952-961.

${ }^{70}$ I.M. Goncalves, M. Murillo and A.M. González, Determination of metals in used lubricating oils by AAS using emulsified samples, Talanta 47 (1998), pp. 1033-1042.

${ }^{71}$ R.J. Brown, Determination of trace metals in petroleum and petroleum products using an inductively coupled plasma optical emission spectrometer, Spectrochim. Acta Part B 38 (1983), pp. 283-289.

${ }^{72}$ E.B.M. Jansen, J.H. Knipscheer and M. Nagtegaal, Rapid and accurate element determination in lubricating oils using inductively coupled plasma optical emission spectrometry, J. Anal. At. Spectrom. 7 (1992), pp. 127-130.

${ }^{73}$ P. Yaroshchyk, R.J.S. Morrison, D. Body and B.L. Chadwick, Quantitative determination of wear metals in engine oils using LIBS: the use of paper substrates and a comparison between single- and double-pulse LIBS, Spectrochim. Acta Part B 60 (2005), pp. 1482-1485.

${ }^{74}$ B.M. Patel and J.D. Winefordner, Graphite rod atomization and atomic fluorescence for simultaneous determination of silver and copper in jet-engine oils, Anal. Chim. Acta 64 (1973), pp. 135-138

${ }^{75}$ R.L. Miller, L.M. Fraser and J.D. Winefordner, Combination flame atomic fluorescence atomic emission DC spectrometer for analysis of trace wear metals in jet engine oils, Appl. Spectrosc. 25 (1971), pp. 477-482

${ }^{76}$ Y. Iwai, T. Honda, T. Miyajima, S. Yoshinaga, M. Higashi, Y. Fuwa, Quantitative estimation of wear amounts by real time measurement of wear debris in lubricating oil, Tribology International, Volume 43, Issues 1-2, January-February 2010, Pages 388-394, ISSN 0301-679X.

77 Machinery Lubrication, accessed from http://www.machinerylubrication.com on $10^{\text {th }}$ September 2010.

${ }^{78}$ LaserNetFines website, accessed from http://www.spectroinc.com/productslasernet-fines.htm on $1^{\text {st }}$ September 2010.

${ }^{79}$ M. P. Sandler, R. E. Coleman, J. A. Patton, Diagnostic Nuclear Medicine, Lippincott Williams \& Wilkins, Philadelphia, 2003.

${ }^{80}$ C.J. Crabtree, Survey of Commercially Available Condition Monitoring Systems for Wind Turbines, Durham University, 2010.
${ }^{81}$ S. Yoon, S. Lee, Y. Lee, J. Oh, A Miniaturized Magnetic Induction Sensor Using Geomagnetism for Turn Count of Small-Caliber Ammunition, Sensors 2006, 6, 712-726.

${ }^{82}$ A. Rajendran, P. Neelamegam, Microcontroller Based Dielectric Constant Measurement, Sensors \& Transducers Magazine, Vol.41, Issue 3, March 2004, pp.181 - 190.

${ }^{83}$ L. M. He, L. L. Kear-Padilla, S. H. Lieberman, J. M. Andrews, Rapid in situ determination of total oil concentration in water using ultraviolet fluorescence and light scattering coupled with artificial neural networks, Analytica Chimica Acta, Volume 478, Issue 2, 22 February 2003, Pages 245-258, ISSN 0003 2670 .

${ }^{84}$ J. F. Hair, Multivariate data analysis : al global perspective ( $7^{\text {th }}$ Edition), Pearson Education, Upper Saddle River, 2009. 